\title{
Could the North Pacific Oscillation Be Modified by the Initiation of the East Asian Winter Monsoon?
}

\author{
YU-HENG TSENG \\ Institute of Oceanography, National Taiwan University, Taipei, Taiwan
}

RUIQIANG DING

State Key Laboratory of Earth Surface Processes and Resource Ecology, Beijing Normal University, Beijing, China

\author{
SEN ZHAO \\ Key Laboratory of Meteorological Disaster of Ministry of Education, and College of Atmospheric Science, Nanjing \\ University of Information Science and Technology, Nanjing, China, and School of Ocean and Earth Science \\ and Technology, University of Hawai' $i$ at Mānoa, Honolulu, Hawaii \\ YI-CHUN KUO \\ Institute of Oceanography, National Taiwan University, Taipei, Taiwan \\ YU-CHIAO LIANG \\ Physical Oceanography, Woods Hole Oceanographic Institution, Woods Hole, Massachusetts
}

(Manuscript received 12 February 2019, in final form 1 December 2019)

\begin{abstract}
This study investigates the modulation of North Pacific Oscillation (NPO) variability upon initiation of the East Asian winter monsoon (EAWM). The data show that the initiation of EAWM in the Philippine Sea strongly connects to the southern lobe variability of the NPO in January followed by a basin-scale oceanic Victoria mode pattern. No apparent connection was found for the northern lobe of the NPO when the ENSO signals are removed. The strengthening of the EAWM in November interacts with the Kuroshio front and generates a low-level heating source in the Philippine Sea. Significant Rossby wave sources are then formed in the lower to midtroposphere. Wave ray tracing analyses confirm the atmospheric teleconnection established by the Rossby wave propagation in the mid- to upper troposphere. Analyses of the origin of wave trajectories from the Philippine Sea show a clear eastward propagating pathway that affects the southern lobe of the NPO from the southern lobe of the western Pacific pattern at $500 \mathrm{hPa}$ and above on the time scale of 20 days. No ray trajectories from the lower troposphere can propagate eastward to influence the central-eastern subtropical Pacific. The wave propagation process is further supported by the coupled model experiments.
\end{abstract}

\section{Introduction}

The North Pacific Oscillation (NPO) is the second leading mode of winter sea level pressure anomalies over the North Pacific (Walker and Bliss 1932; Rogers 1981; Vimont et al. 2003; Linkin and Nigam 2008). It consists of a meridional dipole in the sea level pressure

Corresponding author: Yu-heng Tseng, tsengyh@ntu.edu.tw anomalies with its southern lobe centered near Hawaii and northern lobe over Alaska. The NPO significantly influences downstream weather and climate conditions over North America during the boreal winter (e.g., Rogers 1981; Linkin and Nigam 2008). Hereafter, the seasons referred to are those occurring in the Northern Hemisphere. Recent studies reported that the spring Victoria mode (VM) - the second empirical orthogonal function mode (EOF2) of North Pacific sea surface 
temperature anomalies poleward of $20^{\circ} \mathrm{N}$ (Bond et al. 2003) - is a direct oceanic footprint of the NPO variability (Ding et al. 2015a). The NPO is strongest in winter (Rogers 1981), and the VM reaches a peak around spring as a delayed response to the NPO forces (Ding et al. 2015a). The impacts of the NPO have been examined in many studies. However, its cause and the associated dynamical processes modulating its variability are not completely understood.

Most previous studies have stated that the variability of the NPO is due to stochastic processes in the atmosphere (e.g., Rogers 1981; Furtado et al. 2012). Some recent studies have suggested the nonstationary variability of NPO and its possible connection with the East Asian climate. Wang et al. (2007) found that, before 1975, the NPO was mainly influenced by the El Niño-Southern Oscillation (ENSO) teleconnection with anomalous stationary wave propagation from the subtropical-central Pacific to the northern Pacific. However, after 1975, the NPO was associated with a winter circumglobal wave train pattern over the extratropical region in the Northern Hemisphere, which has been closely linked to the East Asian climate. Pak et al. (2014) further found another nonstationary relationship between the NPO and the East Asian winter monsoon (EAWM) with a sudden change after 1988. This can be associated with the pronounced decadal weakening of the Siberian high system over the Eurasian continent and the eastward migration of the NPO dipole. A strong correlation was found during the 1973-87 strong EAWM epoch, but this vanished during the 1988-2002 weak winter monsoon epoch. These studies suggested the dynamics associated with the origin of NPO and how the NPO may be modulated by the EAWM variability.

The EAWM significantly affects the East Asia and western North Pacific's winter surface climate. This was characterized by a Siberian high, an Aleutian low, and low-level northeasterly monsoon wind blowing from East Asia to the low latitudes over the Asian Marginal Seas (Chen et al. 2000; Wang 2006). Due to the equatorward intrusion of cold air, the enhanced deep convection is often found over the Maritime Continent during winter, leading to an intensified East Asian Hadley circulation as well as the Walker circulations associated with cold air outbreak events (Compo et al. 1999). This suggests that the interannual variability of EAWM may be an atmospheric pathway bridging the tropics and the midlatitude of East Asia.

Here, we explore the relationship between the EAWM and the NPO variability as suggested in many previous studies (e.g., Wang et al. 2007; Pak et al. 2014). More specifically, we focus on the pathway modulating the NPOlike atmospheric variability (specifically the southern lobe of the NPO) initiated by the EAWM, which has not yet been investigated. The main objective is to isolate the dominant role of the EAWM initiation (originating primarily from the Philippine Sea) and its downstream influence on the southern lobe of the winter NPO variability from the observation (no link with the northern lobe of the NPO). The driving mechanism and pathway modulating the NPO are addressed via the Rossby wave ray tracing analyses and the coupled general circulation model (CGCM). Our results confirm that although the EAWM is not directly related to the NPO, the modulation of the NPO variability may be partially deterministic and associated with the initiation of EAWM from the western North Pacific. Section 2 introduces the observational data, the Rossby wave ray tracing method theory, and the modeling experiments. Section 3 investigates the modulation of the NPO variability resulting from the EAWM initiation in the observation. Sections 4 and 5 further validate the associated pathway using the Rossby wave ray tracing and the coupled model experiments. Finally, sections 6 and 7 offer discussion and conclusions.

\section{Data, analysis method, and theory}

\section{a. Observational data}

Three observational datasets for 1958-2017 (60 years) are used here. The monthly sea level pressure, surface wind components, surface latent heat flux, geopotential height, and wind vectors are obtained from the National Centers for Environmental Prediction (NCEP) reanalysis project (Kalnay et al. 1996; Kistler et al. 2001) on a $2.5^{\circ} \times$ $2.5^{\circ}$ horizontal grid resolution. The vertical pressure levels range from 1000 to $100 \mathrm{hPa}$. The climatology of 1986-2015 is removed. The divergence is obtained directly from the velocity fields. We also verify the dynamical processes discussed in this paper using the Twentieth Century Reanalysis (20CR; Compo et al. 2011) from 1958 to 2014. Some minor differences can be found in the amplitude; however, there is no significant difference in terms of the patterns comparing with the NCEP reanalysis product. Therefore, for the sake of consistency, we present all observational results based on NCEP reanalysis.

We also notice that the correlation increases and the pattern strengthens if the data start from 1948 or from 1979. However, the time-dependent unstable relation will not be addressed in this manuscript. The Extended Reconstructed Sea Surface Temperature version 4 (ERSST.v4) data are taken from the National Climatic Data Center on a $2^{\circ} \times 2^{\circ}$ horizontal grid (Smith et al. 2008). All relevant sea surface temperature indices are calculated from the ERSST.v4 data based on the standard definition. The linear trend is removed for all datasets and indices used here. The 

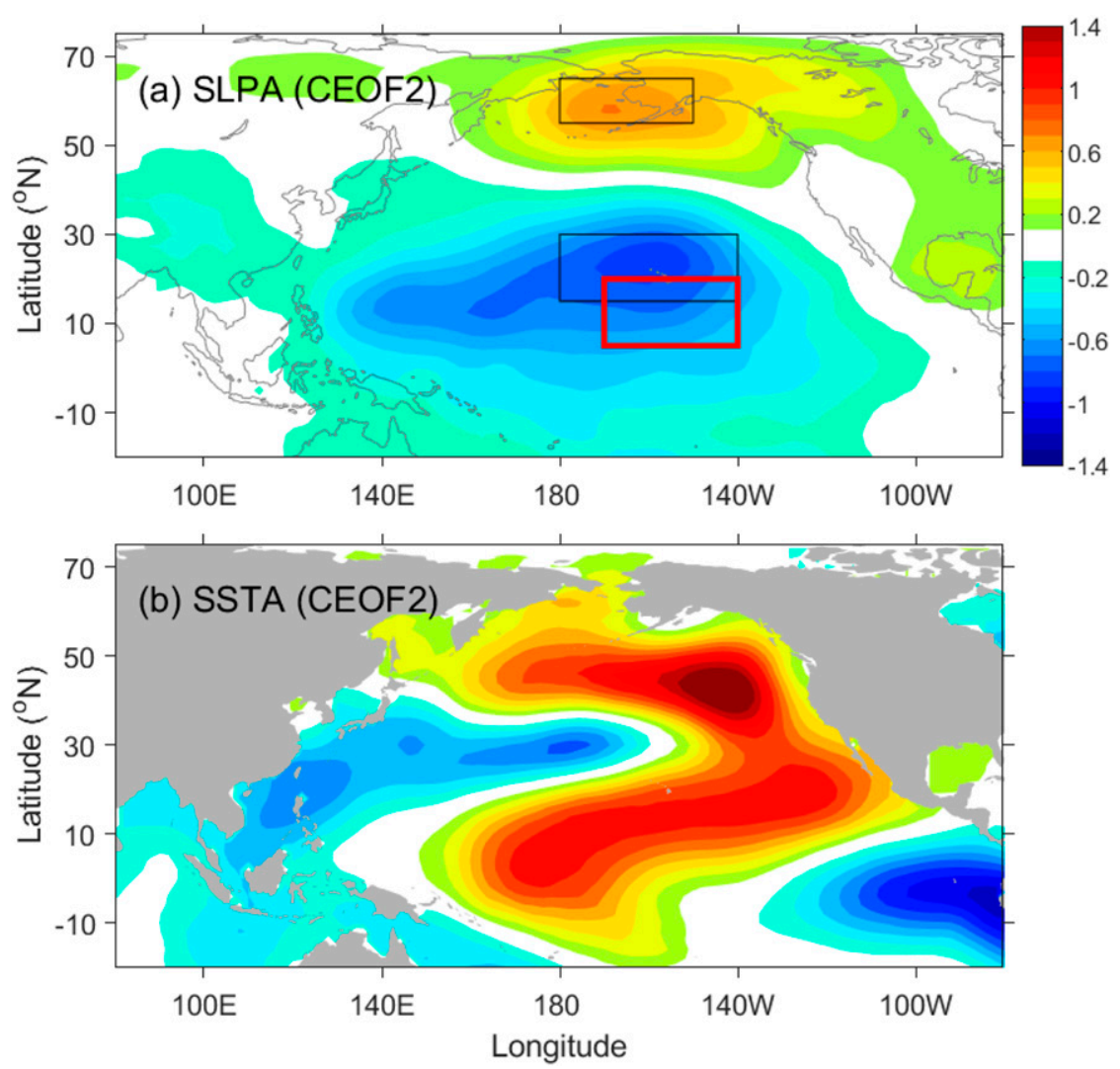

FIG. 1. The second CEOF mode of (a) sea level pressure (hPa) and (b) sea surface temperature anomalies in the North Pacific and tropical Pacific from 1958 to 2017. The two black boxes denote the locations of the area-averaged sea level pressure anomalies used to define the two NPO lobes (northern box: $55^{\circ}-65^{\circ} \mathrm{N}, 180^{\circ}-150^{\circ} \mathrm{W}$; southern box: $15^{\circ}-30^{\circ} \mathrm{N}, 180^{\circ}-140^{\circ} \mathrm{W}$ ). The red box is used to define the southern tip of the $\mathrm{NPO}_{S}$ (represented as $\mathrm{NPO}_{S_{\mathrm{St}}}$ ); see text for detailed information.

statistical significance of the correlations is assessed using a two-sided Student's $t$ test with the degrees of freedom reduced based on the lag-1 autocorrelation following Bretherton et al. (1999).

\section{b. Climate indices}

The representation of the NPO is defined according to the second leading mode of sea level pressure anomalies in the combined empirical orthogonal function (CEOF) analysis of the sea level pressure and sea surface temperature anomalies in Fig. 1 (Tseng et al. 2017). Both fields are normalized by their individual standard deviations before performing the CEOF analysis. Tseng et al. (2017) suggested that this second mode over the North Pacific can better represent the ocean-atmospheric interaction associated with NPO (Ding et al. 2015a). This pattern resembles the NPO's meridional dipole used in Furtado et al. (2012). The two loading centers of the NPO are identified and used to define the NPO's north lobe $\left(\mathrm{NPO}_{N}\right)$ and southern lobe $\left(\mathrm{NPO}_{S}\right)$ indices (i.e., the area-averaged monthly-mean sea level pressure anomalies within the black boxes in Fig. 1a). Furtado et al. (2012) found that the NPO's individual lobes played different roles in the Pacific climate variability. Therefore, these two indices are considered independently.

Several methods have been proposed to define the EAWM index (EAWMI). Wang and Chen (2010) compared the performance of 18 different EAWMI and classified them into four categories. Here, the EAWMI is defined based on the 10-m mean meridional wind within $5^{\circ}-25^{\circ} \mathrm{N}$ and $120^{\circ}-140^{\circ} \mathrm{E}$ (blue box in Fig. 2) where the meridional component of the northeasterly wind along the coasts of East Asia is emphasized (Chen et al. 2000). Many previous studies have documented the vertical structure of EAWM and its connection with the East Asian jet in the midtroposphere (e.g., Leung and Zhou 2015). Although the EAWMI is defined using the northerly wind in the surface layer here, this index reflects the three-dimensional structure of the EAWM system according to a previous study (Yang et al. 2002). 
(a)

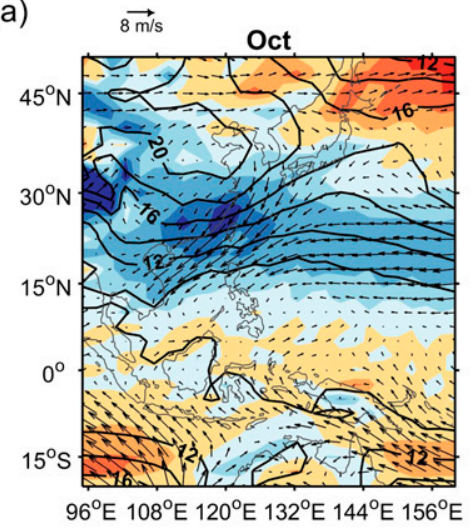

(d)

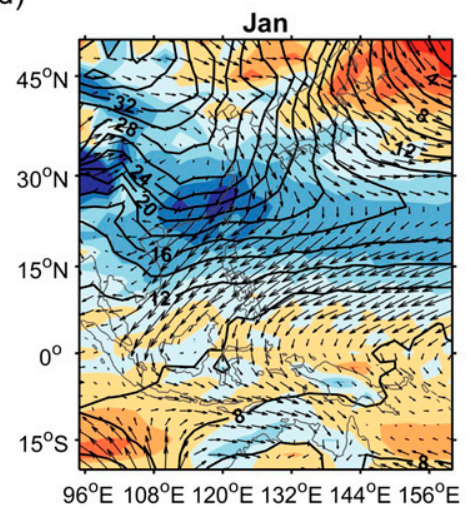

(b)

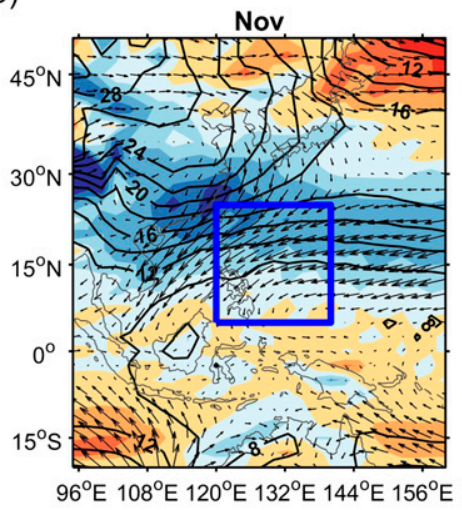

(e)

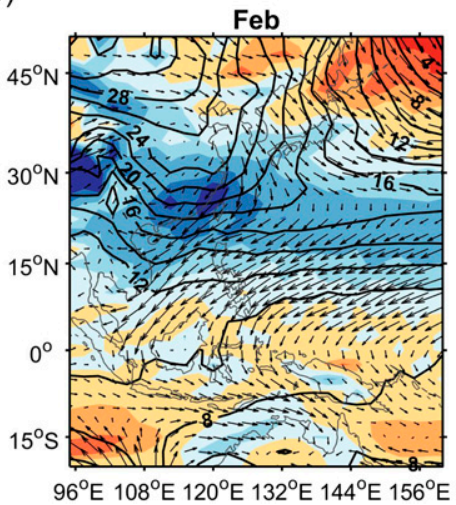

(c)

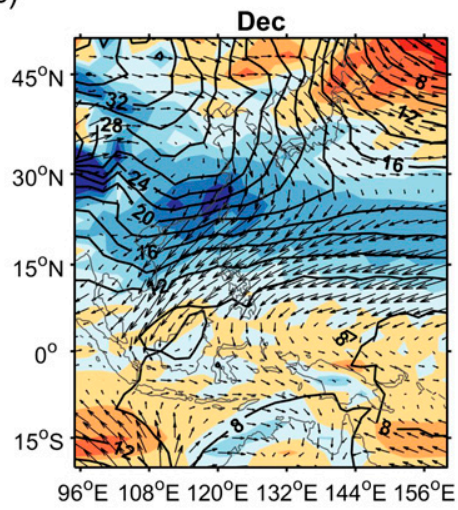

(f)

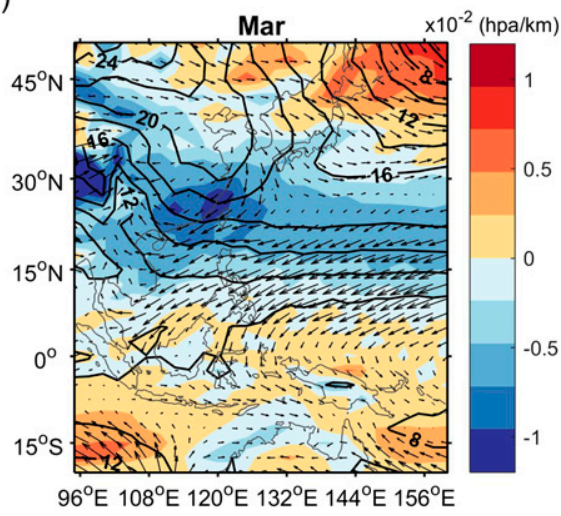

FIG. 2. Climatological sea level pressure (contours, pressure of $1000 \mathrm{hPa}$ is subtracted) from October to March and the corresponding surface winds. The meridional gradients are shown as color shading. The EAWMI is defined by the blue box.

Other common EAWMI are also examined. Our results and conclusions are quite robust as long as the subtropical along-coast northeasterly low-level wind is considered in the indices (mainly reflecting the oceanland contrast). This also suggests that the EAWM indices used in this study relate closely to the southern mode of the EAWM defined in Wang et al. (2010), which is connected to the ENSO variability. The connection found in this study disappears when the Siberian highrelated EAWM indices are used suggesting the independence of the northern mode. We will not address different impacts and relations of EAWM in this study.

Figure 2 shows the climatological sea level pressure (contours) from October to March with the corresponding surface winds (vectors). The meridional pressure gradients (color shading in Fig. 2) associated with the EAWM are intensified after November and become matured later in December and January. The regression of sea level pressure anomalies ( $p<0.1$ is shaded) onto the EAWMI (Fig. 3a) looks very similar to that in Chen et al. (2000). Here, the EAWMI is defined by the averaged EAWMI of November to March as used in Chen et al. (2000). An intense tropical-extratropical interaction associated with the EAWMI can be identified. The regression suggests an obvious contrast between East Asia and the Philippine Sea as well as between the tropics and the midlatitude. Positive regression values are found over Siberia and the Aleutians. The associated surface wind regression confirms the enhanced northeasterlies in the western North Pacific along the East Asian coast (Fig. 3a). An anomalous cyclonic circulation appears over the Philippine Sea. This is associated with a strong confluence over the Maritime Continent and a strong divergence over the eastern Pacific in the tropics consistent with the typical EAWM responses (Chen et al. 2000).

Many previous studies have suggested direct impacts of ENSO on the EAWM (e.g., Wang et al. 2000), and the Niño-3.4 index was linearly removed from the EAWMI hereafter. The removal of the Niño-3.4 index from the data ensures that the EAWMI is linearly independent of tropical Pacific variability. The same regression map of sea level pressure and surface velocity onto the ENSO removed EAWMI can be found in Fig. 3b. Without the linear influence of ENSO, the surface circulation anomalies 

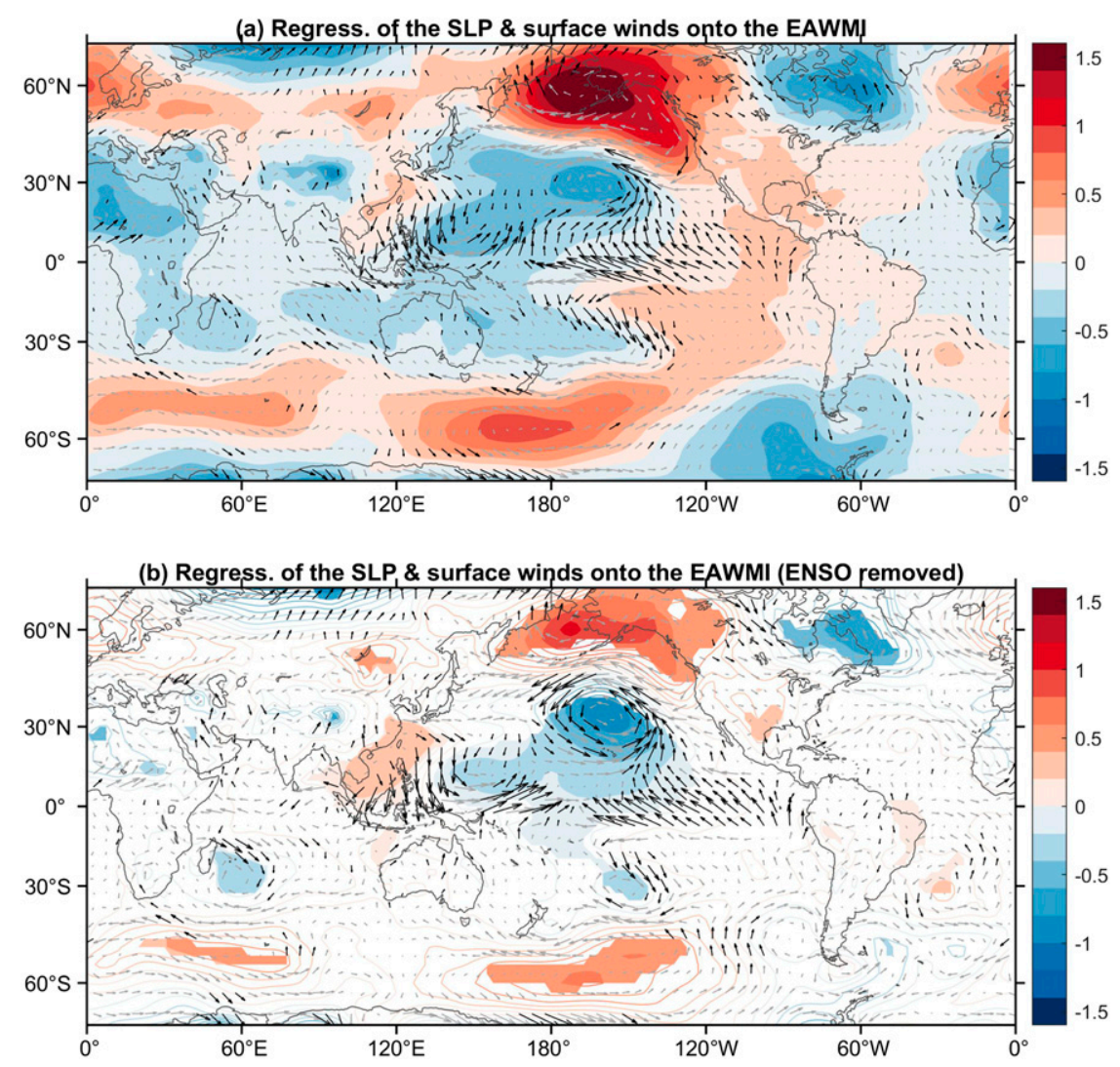

FIG. 3. (a) The regression of sea level pressure ( $p<0.1$ is shaded) and surface wind ( $p<0.1$ is black) anomalies onto the EAWMI. (b) As in (a), but the ENSO signal is removed.

associated with the EAWM are clearly weakened in magnitude - particularly the north lobes of the NPO and the North American dipole (Wang et al. 2015; Ding et al. 2017, 2019). However, the general features of EAWM still exist, and the meridional dipole remains similar to the NPO pattern.

\section{c. Rossby wave source and ray tracing analyses}

We used the linearized Rossby wave source to investigate the Rossby wave source that triggers the Rossby wave patterns in the extratropical regions (Sardeshmukh and Hoskins 1988):

$$
S^{\prime}=\underbrace{\bar{\zeta} \nabla \cdot \mathbf{V}_{\chi}^{\prime}}_{\mathrm{S} 1}-\underbrace{\zeta^{\prime} \nabla \cdot \overline{\mathbf{V}}_{\chi}}_{\mathrm{S} 2}-\underbrace{\mathbf{V}_{\chi}^{\prime} \cdot \nabla \bar{\zeta}}_{\mathrm{S} 3}-\underbrace{\overline{\mathbf{V}}_{\chi} \cdot \nabla \zeta^{\prime}}_{\mathrm{S} 4} .
$$

In the equation above, the overbar and primes represent the climatological mean and perturbation, respectively. The first two terms on the right-hand side indicate the stretching of climatological absolute vorticity by the divergence of anomalous flow $\left(-\bar{\zeta} \nabla \cdot \mathbf{V}_{\chi}^{\prime}\right)$ and the stretching of anomalous vorticity by the climatological divergence $\left(-\zeta^{\prime} \nabla \cdot \overline{\mathbf{V}}_{\chi}\right)$. The last two terms on the right side denote the advection of climatological absolute vorticity by the anomalous divergent flow $\left(-\mathbf{V}_{\chi}^{\prime} \cdot \nabla \bar{\zeta}\right)$ and the advection of anomalous vorticity by the climatological divergent flow $\left(-\overline{\mathbf{V}}_{\chi} \cdot \nabla \zeta^{\prime}\right)$.

Rossby wave ray tracing theory can also provide comprehensive insight into the wave evolution and can characterize the subsequent evolution of the Rossby wave train excited by the tropical heating source (Hoskins and Karoly 1981; Shaman and Tziperman 2005; Zhao et al. 2015; Zhao et al. 2019). Following Li et al. (2015) and Zhao et al. (2015), the dispersion equation for propagation of Rossby wave on a horizontally nonuniform flow with the inclusion of the meridional component may be written as follows:

$$
\omega=\bar{u}_{M} k+\bar{v}_{M} l+\frac{l \partial \bar{q} / \partial x-k \partial \bar{q} / \partial y}{K^{2}} .
$$

Here, $\omega$ is the frequency, $\left(\bar{u}_{M}, \bar{v}_{M}\right)=(\bar{u}, \bar{v}) / \cos \varphi$ is the Mercator projection of the base-state zonal and meridional winds, $\bar{q}=2 \Omega \sin \varphi+\nabla^{2} \bar{\psi}$ is the base-state absolute vorticity, $\varphi$ is latitude, $\Omega$ is the rotation rate of Earth, and $\bar{\psi}$ is the base-state streamfunction. The term $K=\sqrt{k^{2}+l^{2}}$ is the total wavenumber, and $k$ and $l$ are the zonal and 
meridional wavenumbers, respectively. The wave ray is defined as a trajectory that is locally tangential to the group velocity. Using Eq. (2), the group velocity of the Rossby wave packet takes the following form:

$$
u_{g}=\bar{u}_{M}+\left[\left(k^{2}-l^{2}\right) \partial \bar{q} / \partial y-2 k l \partial \bar{q} / \partial x\right] / K^{4}
$$

and

$$
v_{g}=\bar{v}_{M}+\left[2 k l \partial \bar{q} / \partial y+\left(k^{2}-l^{2}\right) \partial \bar{q} / \partial x\right] / K^{4} .
$$

The evolutions of wavenumbers $k$ and $l$ along a trajectory are determined by kinematic wave theory (Whitham 1960) as follows:

$$
\frac{d_{g} k}{d t}=-k \frac{\partial \bar{u}_{M}}{\partial x}-l \frac{\partial \bar{v}_{M}}{\partial x}+\frac{k \partial^{2} \bar{q} / \partial y \partial x-l \partial^{2} \bar{q} / \partial x^{2}}{K^{2}}
$$

and

$$
\frac{d_{g} l}{d t}=-k \frac{\partial \bar{u}_{M}}{\partial y}-l \frac{\partial \bar{v}_{M}}{\partial y}+\frac{k \partial^{2} \bar{q} / \partial y^{2}-l \partial^{2} \bar{q} / \partial x \partial y}{K^{2}},
$$

where $d_{g} / d t=\partial / \partial t+u_{g} \partial / \partial x+v_{g} \partial / \partial y$ represents the material derivative moving with the group velocity.

For each initial zonal wavenumber $k$ and an initial position within the region where the wave source has been perturbed, we use Eq. (2) to solve for the initial meridional wavenumber $l$ by assuming $\omega=0$ (stationary waves). Equations (3) and (4) were then integrated to derive the ray trajectory; they were terminated when the spatial scale of the Rossby waves was less than $1000 \mathrm{~km}$. The background climatological mean wind flow is based on the November-January (NDJ) NCEP reanalysis for the period of 1963-2015. Since the Wentzel-KramersBrillouin approximation used in the Rossby wave theory also requires a slow-varying background flow ( $\mathrm{Li}$ et al. 2015), we also smoothed the background flows of $\bar{u}$ and $\bar{v}$ by multiplying a spherical harmonic component with total wavenumber $n$ by $\exp \left\{-\xi[n(n+1)]^{2}\right\}$ where the coefficient $\xi$ has been set such that the harmonic component of $n=16$ was reduced by $37 \%$. This reduced the potential impacts of the small-scale structures in the basic state. Further studies indicate that the results are not sensitive to the smoothing method applied. Further details can be found in Li et al. (2015) and Zhao et al. (2015).

\section{d. Coupled general circulation model and wave activity flux diagnosis}

The CGCM used in this study is the Community Atmosphere Model version 5 (CAM5; Neale et al. 2012) coupled with a slab (thermodynamic mixed layer) ocean model under the framework of NCAR Community Earth
System Model version 1.2.1 (Danabasoglu and Gent 2009; Hurrell et al. 2013). The spatial resolution of CAM5 is approximately $0.9^{\circ}$ in latitude and $1.25^{\circ}$ in longitude. Thirty layers are discretized vertically with increasing thickness. CAM5 can simulate important large-scale atmospheric circulation features in both the tropics and the midlatitudes (Neale et al. 2012). The resolution of the slab ocean model is nominal $1^{\circ}$, and the model is forced by a monthly-varying ocean heat transport via a $Q$-flux accounting for the effects of horizontal advection and vertical entrainment (Danabasoglu and Gent 2009). The slab ocean model has an active thermodynamic process so that the thermodynamic feedback such as the windevaporation-sea surface temperature feedback can be included in the model simulation.

To explore the role of the stationary wave in linking EAWM variability to NPO, we calculated quasi-stationary wave activity fluxes (WAFs) following Takaya and Nakamura (2001). The WAF in spherical coordinates can be formulated as follows:

$$
\begin{aligned}
W_{x}= & \frac{p \cos \phi}{2|\mathbf{U}|}\left\{\frac{U}{(a \cos \phi)^{2}}\left[\left(\frac{\partial \psi^{\prime}}{\partial \lambda}\right)^{2}-\psi^{\prime} \frac{\partial^{2} \psi^{\prime}}{\partial \lambda^{2}}\right]\right. \\
& \left.+\frac{V}{a^{2} \cos \phi}\left[\frac{\partial \psi^{\prime}}{\partial \lambda} \frac{\partial \psi^{\prime}}{\partial \phi}-\psi^{\prime} \frac{\partial^{2} \psi^{\prime}}{\partial \lambda \partial \phi}\right]\right\} \\
W_{y}= & \frac{p \cos \phi}{2|\mathbf{U}|}\left\{\frac{U}{a^{2} \cos \phi}\left[\frac{\partial \psi^{\prime}}{\partial \lambda} \frac{\partial \psi^{\prime}}{\partial \phi}-\psi^{\prime} \frac{\partial^{2} \psi^{\prime}}{\partial \lambda \partial \phi}\right]\right. \\
& \left.+\frac{V}{a^{2}}\left[\left(\frac{\partial \psi^{\prime}}{\partial \phi}\right)^{2}-\psi^{\prime} \frac{\partial^{2} \psi^{\prime}}{\partial \phi^{2}}\right]\right\} .
\end{aligned}
$$

Here, $p$ denotes the pressure divided by $1000 \mathrm{hPa} ; \mathbf{U}=(U$, $V, 0)$ where $U$ is the mean zonal wind, $V$ is the mean meridional wind, $a$ is Earth's radius, $f$ is the Coriolis parameter, $\phi$ is the latitude, $\lambda$ is the longitude, $z=-H \ln p$ (scale height $H=8 \mathrm{~km}$ ), and $N^{2}$ is the buoyancy frequency. The WAF calculation following Takaya and Nakamura (2001) considers a zonally varied background flow. This is a general form of the WAF derived in Plumb (1985). Because the spatially varied jet serves as a waveguide to affect the Rossby wave propagation (Hoskins and Ambrizzi 1993), we show the WAF results following Takaya and Nakamura (2001) in this study although consistent results can also be obtained using Plumb's method.

\section{Link between the EAWM and the NPO}

The NPO and its accompanying ocean surface footprint, the VM, have been connected with ENSO variability (e.g., Chang et al. 2007; Ding et al. 2015a; Tseng et al. 2017). These surface expressions can be explained 
using the second dominant CEOF of sea level pressure and sea surface temperature anomalies in the Pacific (Figs. 1a,b). This meridional dipole of NPO pattern is very similar to that reported earlier (Linkin and Nigam 2008; Furtado et al. 2012) and is a robust winter atmospheric feature. The oceanic footprint of the VM in Fig. $1 \mathrm{~b}$ shows a region of cold sea surface temperature anomalies extending from the western North Pacific to the Kuroshio Extension. This is encircled by warm sea surface temperature anomalies around the North Pacific coast reaching the central tropical Pacific (Bond et al. 2003; Di Lorenzo et al. 2008; Ding et al. 2015a; Tseng et al. 2017). The most recent warm blob observed in the northeastern Pacific evolved from late 2013 to 2016. This is a typical example connecting the VM with the ENSO evolution (Di Lorenzo and Mantua 2016; Tseng et al. 2017). However, these recent studies only address the evolution of the VM in the El Niño events and the multiyear persistence restrengthened by the NPO. They did not address any process potentially related to the development of the NPO.

The EAWM connects with the variability of the NPO although the linkage is not stationary (e.g., Wang et al. 2007; Pak et al. 2014). Previous studies also suggested that the winter sea surface temperature in the western North Pacific may affect the NPO/VM (e.g., Wang et al. 2012; Tseng et al. 2017). The relationship between the EAWM and the NPO should be re-examined. Figure 4 shows the observed lead-lag correlation between the EAWMI and the NPO-related sea level pressure anomalies (see Fig. 1 for the regions). Similar to the EAWMI, the Niño-3.4 index is also linearly removed from all fields to avoid any ENSO impact. Moderate correlation can be found for the sea level pressure anomalies in the regions of $\mathrm{NPO}_{S}$ and $\mathrm{NPO}_{N}$, suggesting the potential link between the EAWM and the NPO discussed earlier. However, the largest correlation can be found when the November EAWMI leads the southern tip of the $\mathrm{NPO}_{S}$ anomalies (defined as $\mathrm{NPO}_{S_{\mathrm{St}}} ; 5^{\circ}-20^{\circ} \mathrm{N}, 170^{\circ}-140^{\circ} \mathrm{W}$, the red box in Fig. 1) by two months $(R=0.50)$. This region is just above the southern branch of the VM in Fig. $1 \mathrm{~b}$ and is the region where the southern lobe of the NPO starts to initiate the $\mathrm{VM}$ or so-called meridional mode through the seasonal footprinting mechanism (Chang et al. 2007; Ding et al. 2015a). The correlations are generally higher after 1979.

Due to the observed lead-lag correlation, the initiation of the EAWM might influence the development of the NPO through atmospheric teleconnection during the early winter (NDJ). The mechanism and the sequential teleconnection may be initiated from the early stage of the EAWM variability (further discussed in section 6). Figure 5 shows the correlation map of the monthly EAWMI with several lags of sea level pressure and wind anomalies over North Pacific (0-3 months). During November (no lag), the EAWMI is associated with a pair of cyclonic and anticyclonic circulations above the subtropical western North Pacific and South China Sea, respectively. The simultaneous large correlation can be found along the coast of China from the South China Sea (SCS) to the Yellow Sea (maximum correlation $R=0.73$ ), indicating the strong geostrophic wind structure. This is consistent with the strengthening of the EAWM characterized by a clear contrast above the land and the ocean separated by the strong northeasterly. Another comparable large correlation can be found when the November EAWMI leads the sea level pressure anomalies by 2 months in the region just above the southern branch of the VM. This is consistent with the observed lead-lag correlation in Fig. 4. The northeastward surface wind is also favorable for the development of the VM.

The time series of November EAWMI, January $\mathrm{NPO}_{S}$, and January $\mathrm{NPO}_{S_{\mathrm{St}}}$ are shown further in Fig. 6a. There is very good correspondence between the November EAWMI and January $\mathrm{NPO}_{S_{\mathrm{St}}}$ especially after 1980. This is consistent with the increased correlation shown in the bottom panel of Fig. 4. The high correlation can be further extended to December EAWMI with a 3-month lag in March. This extended impact is associated with the spring footprint of the VM resulting from the NPO forcing. Furtado et al. (2012) suggested a large distinction in the dynamics between the northern and southern lobes of the NPO, with the southern lobe of the NPO likely linked to the central tropical Pacific at the decadal time scale. This viewpoint is supported by the significant correlation in Fig. 4 while the moderate lead-lag correlation differs for the northern and southern lobes of the NPO. They also showed that the southern lobe of the NPO contains both high- and low-frequency modes. Our results suggest the direct impact of the EAWM in modulating the NPO within two months consistent with the high-frequency peaks shown in Furtado et al. (2012). The correlation is even higher if the NCEP reanalysis data are extended to 1948.

The two-month lag near the southern lobe of the NPO (i.e., the $\mathrm{NPO}_{S_{\mathrm{St}}}$ ) and the extended lag to spring are not a coincidence. Our results suggest that the November initiation of the EAWM can induce the low-level convergence/ divergence change in the Philippine Sea generating a potential heating source associated with the simultaneous response to sea surface temperature (Wang et al. 2012) and modulating the central-subtropical Pacific dynamics two months later. Figure 7 shows the correlation map between the November EAWMI with the geopotential height anomalies (top to bottom: 200, 500, and $1000 \mathrm{hPa}$, respectively) for November and two consecutive lag 

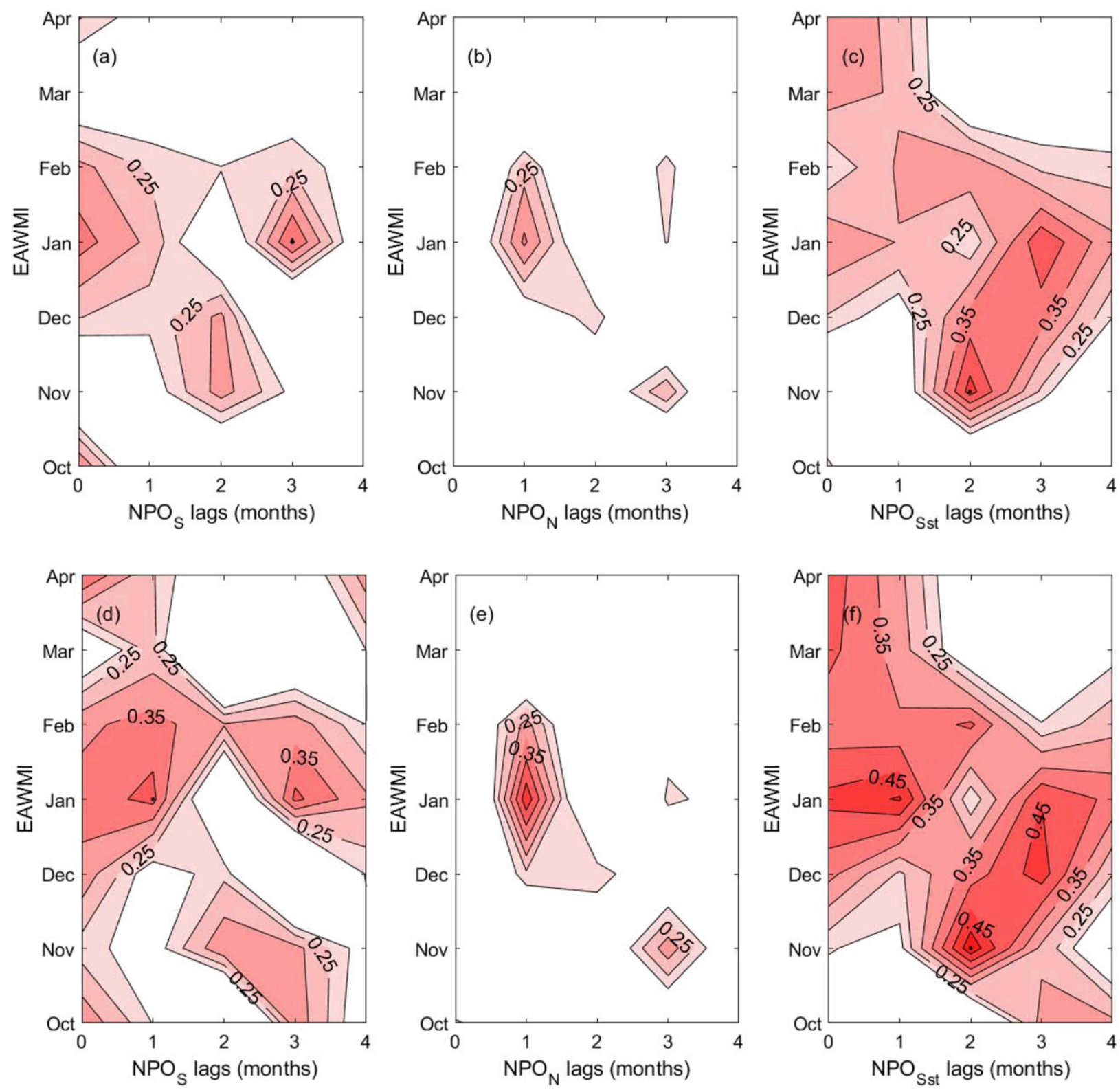

FIG. 4. Observed lead-lag correlation between the EAWMI and (a) the $\mathrm{NPO}_{S}$, (b) $\mathrm{NPO}_{N}$, and (c) $\mathrm{NPO}_{S_{\mathrm{St}}}$, respectively. The $\mathrm{NPO}_{S}$ and $\mathrm{NPO}_{N}$ represent the averaged sea surface pressure anomalies in the black box shown in Fig. 1. Significant correlation can be found in

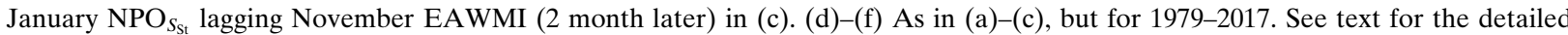
definition. Here $p<0.1$ is shaded. The ENSO signal is removed.

months (December and January). The simultaneously large positive (negative) correlation in November is clear at $1000 \mathrm{hPa}$ over the western North Pacific (East Asia), consistent with Fig. 5. The zonally oriented dipole at $1000 \mathrm{hPa}$ changes to a meridionally oriented dipole at higher levels. The meridional dipole is more evident at 500 and $200 \mathrm{hPa}$. The meridional structure is similar to the typical barotropic western Pacific (WP) teleconnection pattern (Linkin and Nigam 2008; Chow et al. 2017), but the location shifts slightly southward. The large correlation of the EAWMI with November outgoing longwave radiation (OLR) anomalies and divergence fields further suggested that the Rossby wave sources are generated above the Philippine Sea along the coast of East Asia in Figs. 8a and 8c. The strong negative OLR is not only confined within the coastal region but also extends offshore. Particularly, the low-level divergence field in November (Fig. 8c) shows a strong low-level convergence just above the Kuroshio front: This is also associated with a downstream low-level divergence in the climatologically warm pool. A strong 

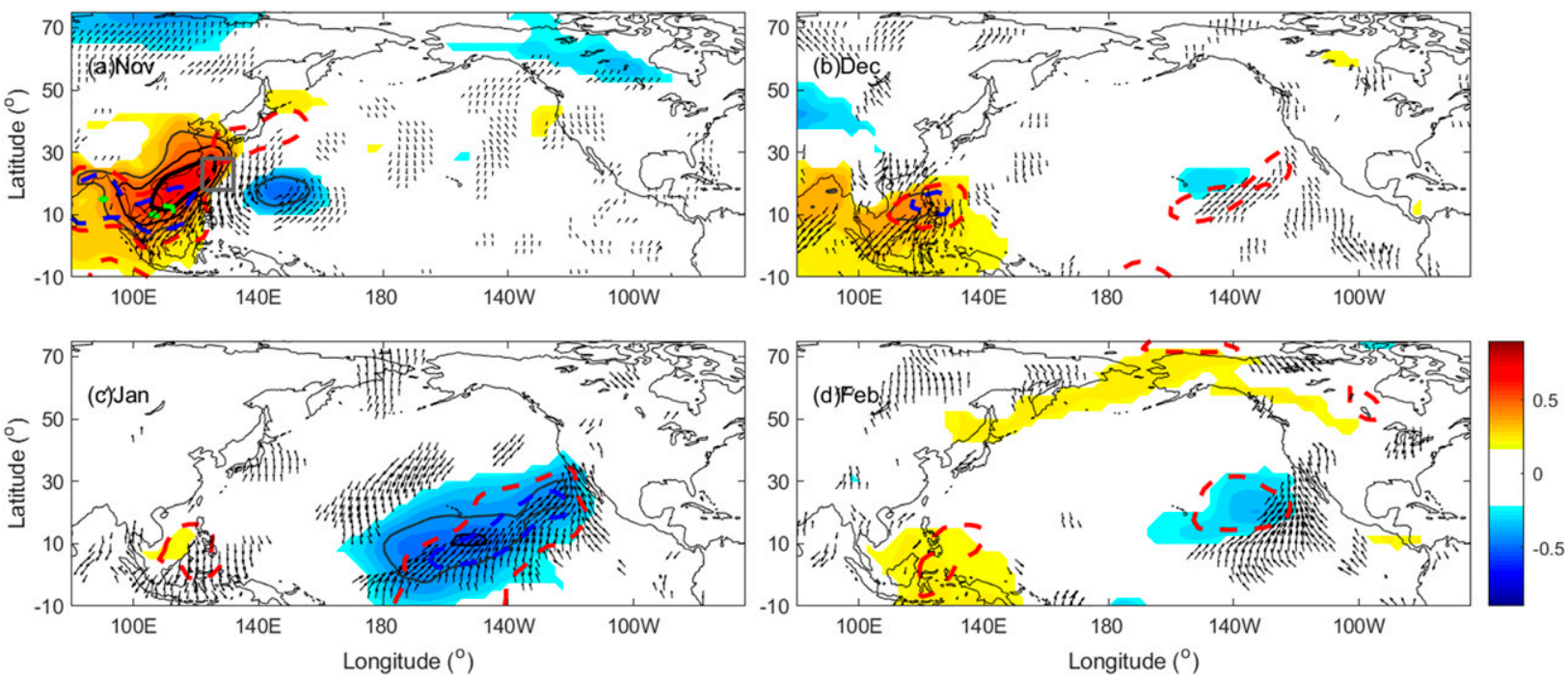

FIG. 5. Correlation map of the November EAWMI with several lags of surface pressure and wind anomalies (0-3 months); (a) November (no lag), (b) December, (c) January, and (d) February. The contour lines correspond to $R=0.6$ (bold black), 0.5 (thin black), and 0.4 (gray). The sea surface temperature index defined in Wang et al. (2012) is shown as the gray box in (a). Additional thick dashed contours represent similar lag correlations of sea level pressure anomalies with the November sea surface temperature index (Wang et al. 2012) for $R=0.5$ (blue) and 0.4 (red). The ENSO signal is removed.

and extended divergence can also be found above the Kuroshio front at $200 \mathrm{hPa}$ suggesting a typical deep convection in the Philippine Sea connected to the southern lobe of the NPO in January.

This atmospheric teleconnection may likely result from the development of Rossby wave train. In December, the remote atmospheric teleconnection associated with the November EAWMI starts to emerge and evolve in the eastern North Pacific (middle panel in Fig. 7) with an enhanced WP pattern at $200 \mathrm{hPa}$ in the western North Pacific. This suggests a propagation speed of one month for the teleconnection pattern. However, the largest correlation occurs in the correlation map of January over the southern branch of the VM in the lower troposphere (right panel in Fig. 7), suggesting a continuously enhanced process to strengthen the winter NPO that matures in January (Ding et al. 2015a). The surface wind-evaporation-sea surface temperature feedback may further enhance the

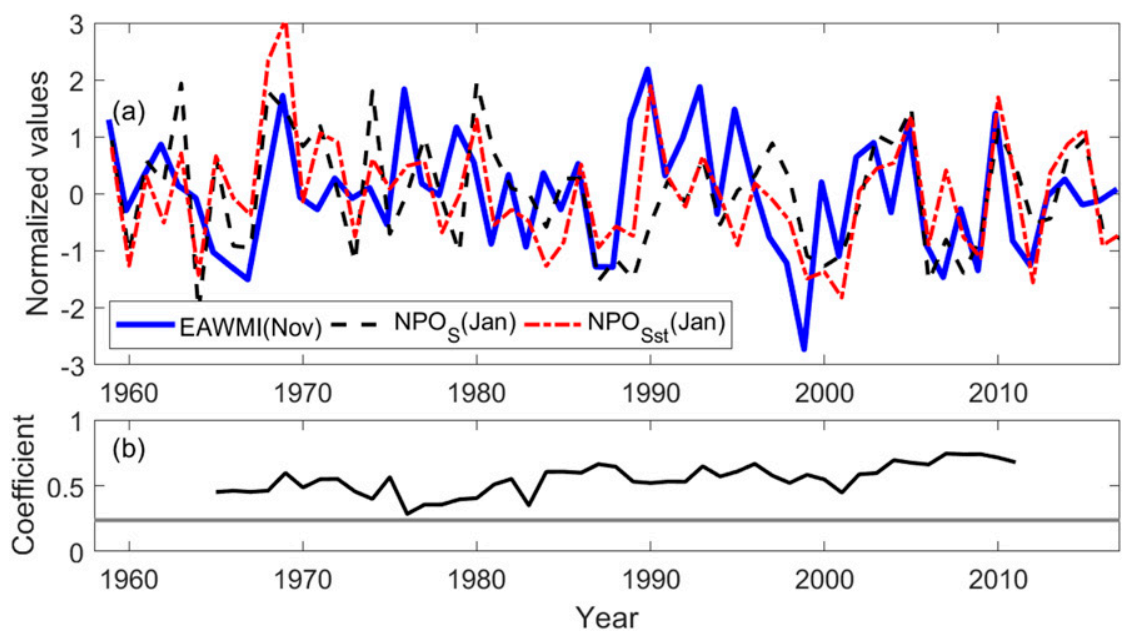

FIG. 6. (a) Time series of November EAWMI, January $\mathrm{NPO}_{S}$, and January $\mathrm{NPO}_{S_{\mathrm{st}}}$, respectively. All time series are aligned with their corresponding months. (b) 13-yr running correlation coefficient between November EAWMI and the $\mathrm{NPO}_{S_{\mathrm{St}}}$. The horizontal line indicates the $90 \%$ confidence level. ENSO signal is removed. 

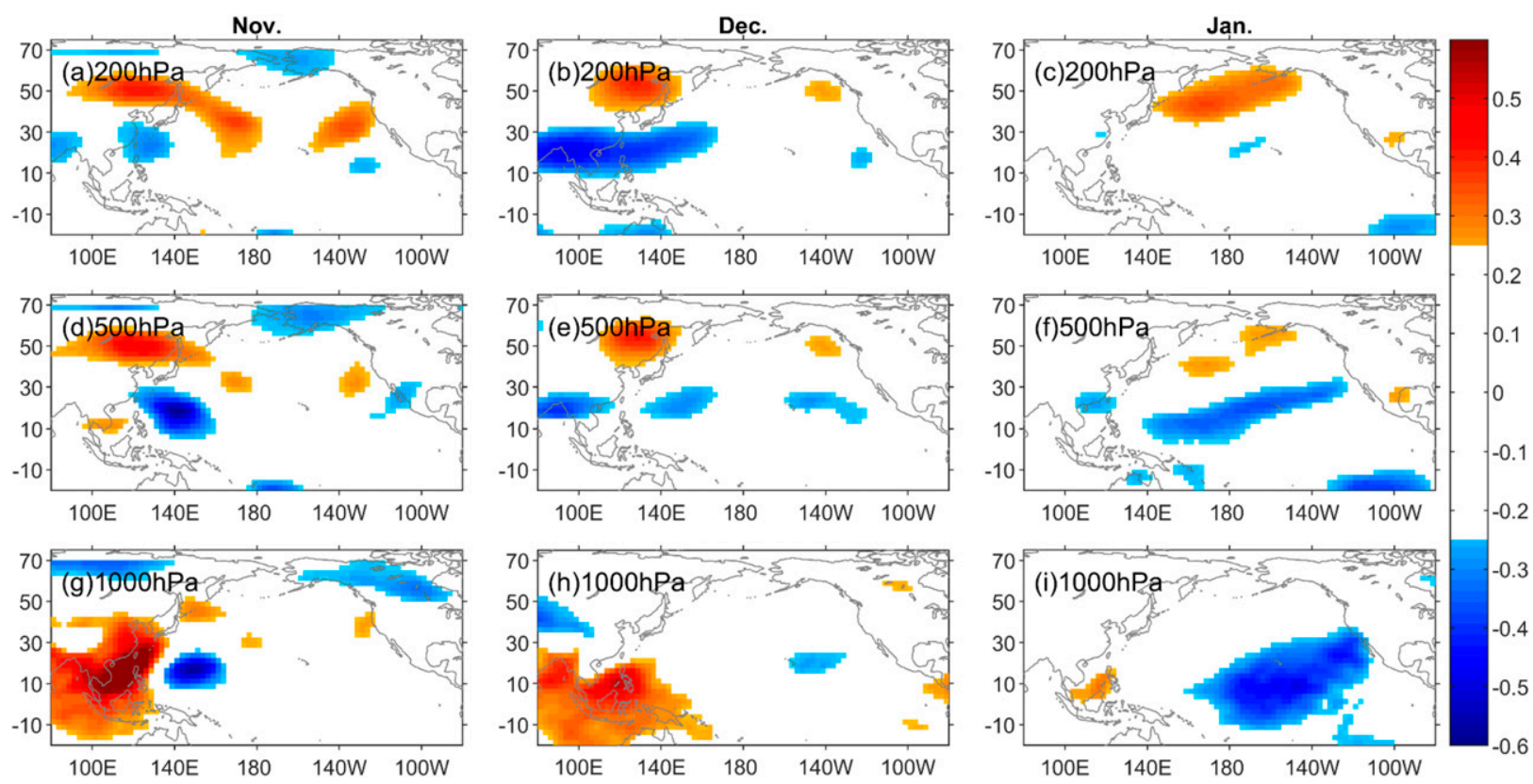

FIG. 7. Correlation maps between the November EAWMI and the geopotential height anomalies for (top three panels) 200, 500, and $1000 \mathrm{hPa}$, respectively, for November and two lag months (December and January). Only $p<0.1$ is shown. The ENSO signal is removed.

ocean-atmosphere interaction in this particular region (Chang et al. 2007; Ding et al. 2015a), and it is not surprising to see that high correlation decreases with height. This provides additional evidence of the tight relation between the NPO and VM (Ding et al. 2015a). Furthermore, the completed process is also associated with a band of convergence in the $200 \mathrm{hPa}$ (Fig. 8f) and positive OLR (Fig. 8b) above the southern branch of the VM in January, suggesting a strong top-down response on the sea level pressure anomalies and the lack of upper troposphere response in the geopotential height. These results show a propagating atmospheric teleconnection in the mid- to upper troposphere that affects the southern lobe of the NPO. We will further examine the Rossby wave train development in the next section.

\section{Rossby wave train mechanism}

The observational data in section 3 suggest a link between the initiation of the EAWM and the southern lobe of the NPO. This link may involve the heating source above the Kuroshio front and the divergence/ convergence in the upper troposphere. The propagation is also within a month (Fig. 7). To further explore the described pathway from the Philippine Sea, we examined the potential Rossby wave source that may trigger the Rossby wave patterns in the extratropical regions.

Figure 9 shows the regressed Rossby wave source in the upper, middle, and lower troposphere onto the EAWMI.
With strengthening of the EAWM, there are significant Rossby wave sources (local positive vorticity tendency) in the lower $(850 \mathrm{hPa})$ and middle $(500 \mathrm{hPa})$ troposphere over zonally oriented regions from southern China and the northern Philippine Sea $\left(20^{\circ}-40^{\circ} \mathrm{N}, 110^{\circ}-140^{\circ} \mathrm{E}\right)$. This region is consistent with the large negative OLR region shown in Fig. 8a confirming the previous speculation. We found that the Rossby wave source is dominated by the stretching of climatological absolute vorticity by the EAWM-related divergence anomalies $\left(-\bar{\zeta} \nabla \cdot \mathbf{V}_{\chi}^{\prime}\right)$ and the advection of climatological absolute vorticity by the anomalous EAWM-related divergent flow $\left(-\mathbf{V}_{\chi}^{\prime} \cdot \nabla \bar{\zeta}\right)$ (figures not shown).

A theoretical wave ray tracing approach was next used to analyze the potential atmospheric teleconnection during NDJ. These theoretical analyses examine if the subsequent evolution of the Rossby wave train excited by the heating source from the Philippine Sea can further influence the eastern North Pacific (and thus the strength of the $\mathrm{NPO}_{S}$ ). Figure 10 shows the wave ray trajectories initiated by the heating sources (crosses) under the climatological NDJ basic flows in the troposphere and integrated for 20 days. The initial position arrays $\left(5^{\circ}-30^{\circ} \mathrm{N}\right.$, $110^{\circ}-140^{\circ} \mathrm{E}$ ) are selected by the significant Rossby wave source region (also large negative OLR anomalies; Figs. 8 and 9). The wave source is not very effective at generating the poleward Rossby waves since the basic flow is easterly without significant meridional flow (Li et al. 2015; Zhao et al. 2015). The results shown here are for both positive 

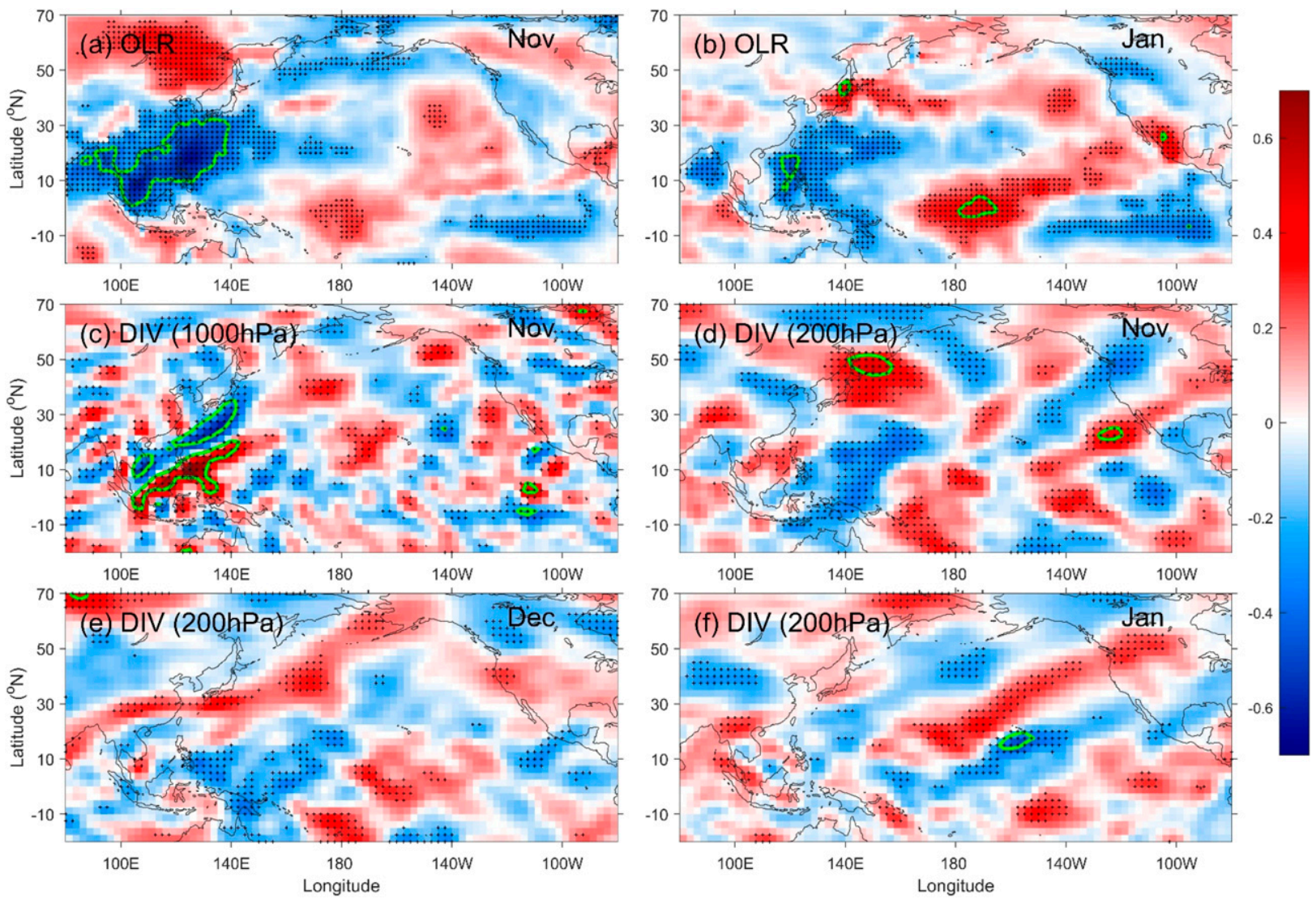

FIG. 8. Correlation maps between the November EAWMI and the (a) November and (b) January OLR anomalies and the November divergence at (c) 1000 and (d) $200 \mathrm{hPa}$, respectively. (e),(f) The correlation maps between the November EAWMI and 200-hPa divergence in the following December and January. The plus shading represents $p<0.1$. Correlation $R=0.4$ is shown as green. The ENSO signal is removed.

and negative initial meridional wavenumber $l$ to reflect initially northward and southward propagation of stationary waves, respectively.

In the midtroposphere $(500 \mathrm{hPa})$, the sources over the northern region (north of $15^{\circ} \mathrm{N}$ ) can indeed excite two branches of waves that propagate eastward to the North Pacific sector: The northern branch is poleward and reflected equatorward at midlatitudes (about $60^{\circ} \mathrm{N}$ for $k=2$ ). The other southern branch is equatorward and reflected poleward at the latitudes where the zonal winds equal zero $\left(U=0\right.$; about $\left.15^{\circ}-20^{\circ} \mathrm{N}\right)$. A major part of the northern branch finally arrives in the central-eastern North Pacific over the southern branch of the VM before moving eastward to the Americas. Trajectories based on the initial zonal wavenumbers $k=4$ and $k=6$ exhibit qualitatively similar paths except that waves with a smaller zonal wavenumber can propagate to higher latitudes before equatorward reflection. These two branches of waves confine the wave activity to the North Pacific sector and confirm that the specified sources can potentially modulate the NPO variability after 20 days-specifically the southern lobe over the southern branch of the VM. This central-eastern North Pacific region is also consistent with the largest correlation between November EAWMI and the January geopotential height at $500 \mathrm{hPa}$ shown in Fig. 7 (this is also seen in December but is weaker). Based on the NDJ climatological winds, our integration of wave ray equations indicates that the energy transfer from the source locations can reach the south lobe of NPO in 20 days or within the 1-2-month lag shown above (see more discussion in section 6). Although the trajectories cover a wide range of the North Pacific, the large convergence over the southern branch of the VM at $200 \mathrm{hPa}$ (Fig. 8f) suggests a direct top-down impact on the low levels only when the trajectories reach this area.

In contrast, the southern sources (south of $15^{\circ} \mathrm{N}$ ) cannot excite the waves that can spread eastward. All trajectories are moving westward into the tropical western Pacific. This suggests that the meridional locations in the Philippine Sea critically matter. Only the sources within the southern lobe of the WP teleconnection pattern-that is, north of about 

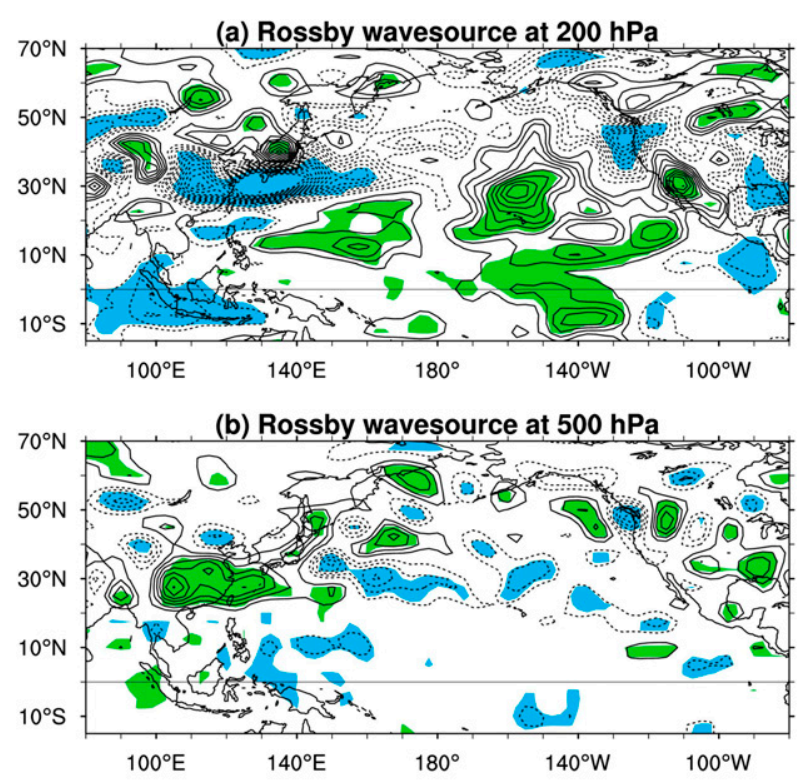

(c) Rossby wavesource at $850 \mathrm{hPa}$

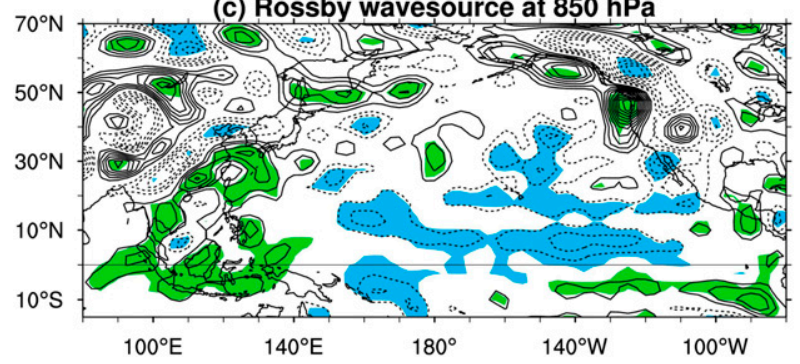

FIG. 9. Regressed Rossby wave source at (a) 200, (b) 500, and (c) $850 \mathrm{hPa}$ onto the EAWMI. The contour interval is $10-11 \mathrm{~s}^{-2}$ $\left(\mathrm{m} \mathrm{s}^{-1}\right)^{-1}$. Regression coefficients with $p<0.1$ is shaded as green (positive) and blue (negative).

$15^{\circ} \mathrm{N}$ (Wallace and Gutzler 1981; Chow et al. 2017), which is also over the warm Kuroshio recirculation (Tseng et al. 2012) - can influence the southern lobe of the NPO, consistent with the strong connection between the WP and NPO patterns (Linkin and Nigam 2008).

Similar wave ray trajectories can also be found at $250 \mathrm{hPa}$ (top panel of Fig. 10), but the number of trajectories reaching the central-eastern North Pacific is reduced. More trajectories recirculate anticyclonically at $250 \mathrm{hPa}$ than $500 \mathrm{hPa}$ for $k=2$ (i.e., belonging to the southern sources). This is mainly because the vertical structure of the WP tilts northeastward with increased altitudes (similar to the November correlation map shown in the left panel in Fig. 7). Further, the wave trajectories affecting the southern lobe of the NPO are also reflected more strongly at lower latitudes ( $250 \mathrm{vs} 500 \mathrm{hPa}$ ), mainly due to the stronger jet stream in $250 \mathrm{hPa}$.

The trajectories are entirely different in the low troposphere. Nearly all rays propagate westward and cannot propagate to the central-eastern North Pacific under the
850-hPa circulation condition (bottom panel in Fig. 10). This is due to the enhanced southwestward EAWM. In general, our wave ray tracing analysis, consistent with the NDJ observation shown in section 3, provides evidence that the specified sources can significantly contribute to the variability of the NPO pattern via the Rossby wave propagation. This impact is strongest between 600 and $400 \mathrm{hPa}$ during the NDJ background flow configurations and is directly related to the southern lobe of winter WP pattern. We note that only the stationary waves are discussed here because of the climatological winds. The disturbances develop at the group velocity with a zero phase stationary velocity.

\section{Coupled general circulation model sensitivity experiments}

The results from previous section (in addition to the observations in Figs. 5-8) suggest that there may be a deep convective heating source associated with EAWM initiation (as discussed in section 6). This likely results from the cold EAWM air blowing over the warm Kuroshio front. We conducted CGCM sensitivity simulations to further support the findings in the reanalysis datasets as well as the potential pathway suggested in section 4. A control CGCM simulation was integrated for 30 years forced by the monthly $Q$ flux initially derived from a fully coupled simulation. A control run and a sensitivity forced experiment ( $Q$ flux is enhanced by $10 \%$ in the defined EAWM region) are run for another 45 years from the end of the control simulation above as the initial condition. The control run continues to use the default $Q$ flux while the forced simulation uses the same forces except an enhanced $Q$ flux in the EAWM region defined in section $2 \mathrm{~b}$ from November and December. The $10 \%$ increase in the $Q$ flux magnitude (negative value indicates heat release from the ocean into the atmosphere above) is included to mimic the enhanced heating source associated with the EAWMI (Figs. 11a,b) where a large OLR correlation is found (Fig. 8).

The simulated November differences of the mean geopotential height at 500 and $200 \mathrm{hPa}$ between the enhanced heating experiment and control run are shown in Figs. 12a and 12b while the corresponding OLR difference is presented in Fig. 12c. Consistent with the observations of geopotential height in Fig. 7 and OLR in Fig. 8, the footprint in the northeastern Pacific quickly emerged in the model differences in the mid- to upper troposphere as a result of the heating associated with the EAWMI although the patterns differ. These minor differences in the patterns can be attributed to the missing interactive ocean dynamics in the current slab ocean coupled model (not the main focus of this study). Our CGCM sensitivity experiments confirm that the observed heating in the 

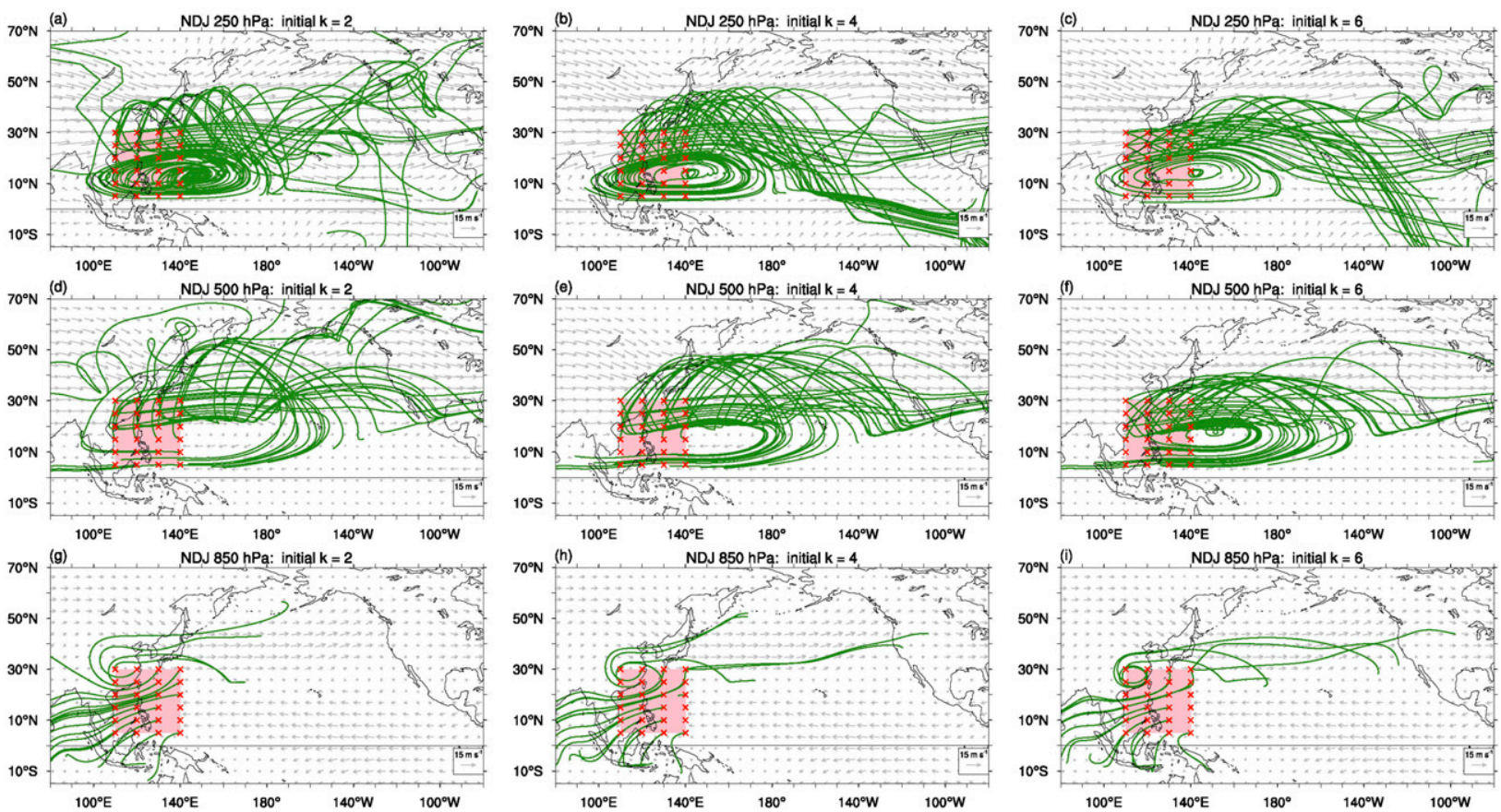

FIG. 10. The stationary Rossby wave ray trajectories (green curves) with initial zonal wavenumber $k=($ left to right) 2,4 , and 6 under the NDJ climatological flows (gray vectors) for the period of 1965-2012 at (a)-(c) 250, (d)-(f) 500, and (g)-(i) $850 \mathrm{hPa}$. Red forks over pink shadings denote wave source arrays over the western North Pacific $\left(5^{\circ}-30^{\circ} \mathrm{N}, 110^{\circ}-140^{\circ} \mathrm{E}\right)$.

Philippine Sea indeed serves as a local Rossby wave source in the western North Pacific and impacts the southern lobe of NPO within the time scale of a month. However, the footprint of sea level pressure appears late in the northeastern Pacific during January (see the large January mean sea level pressure differences between the enhanced heating experiment and control run in Fig. 12d). The enhanced heating causes clear low pressure anomalies in the northeastern Pacific consistent with the observations in Fig. 5c. These anomalies result from the Rossby wave propagation and the amplification of typical wind-evaporation-sea surface temperature feedback in the southern lobe of the NPO as discussed in the previous sections. The oceanatmosphere interaction in the northeastern Pacific requires time to evolve. We note that the observed low pressure anomalies extend more southwestward toward the central Pacific than the modeled differences. This is also due to the missing ocean dynamics.

Next, we calculate the WAF differences to further examine the EAWM-related wave pathway identified in the observational datasets between the control and forced CGCM simulations (see section $2 \mathrm{~d}$ for details). Figures 11c-f compare the WAF differences at 200 and $500 \mathrm{hPa}$, respectively. At $500 \mathrm{hPa}$ in November, the WAF differences show a waveguide pathway from the forcing region in the southeast of Japan, which then turns northeastward to the Gulf of Alaska. The WAF is mainly initiated from the warm side of the Kuroshio front consistent with the significant OLR in Fig. 12c. This suggests that enhanced low-level heating in the WNP may enhance the pathway discussed above. The WAF differences at 200 and $500 \mathrm{hPa}$ show very similar results and suggest the strong barotropic structure.

In December, the WAF differences look quite similar but the strength and the direction vary from November as a cyclonic WAF is nearly formed in the northeastern Pacific. We note that the significant WAF can be found over the Kuroshio Extension region possibly due to the prevailing background mean westerlies in the model (shading is the zonal mean speed in Figs. 11c-f). These results are largely consistent with the Rossby wave pathway suggested by the ray tracing theory and further support our observations.

\section{Discussion}

A new pathway is proposed to modify the NPO-like atmospheric variability (specifically the southern lobe) resulting from the initiation of EAWM. This offers a new perspective on the assumed stochastic dynamics of NPO and tightly connects the EAWM with the NPO variability. Prior studies on the NPO have mainly focused on the impacts of its teleconnection patterns on the weather and climate of North America (Linkin and Nigam 2008) and 
(a) Nov Q-flux difference

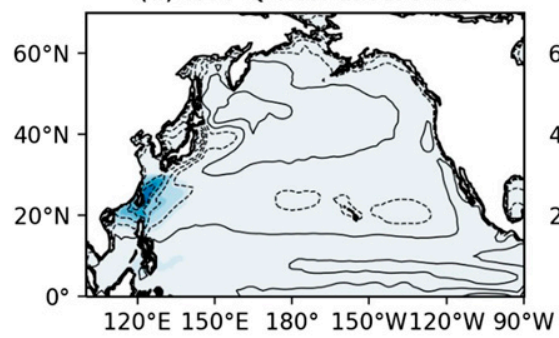

(b) Dec Q-flux difference

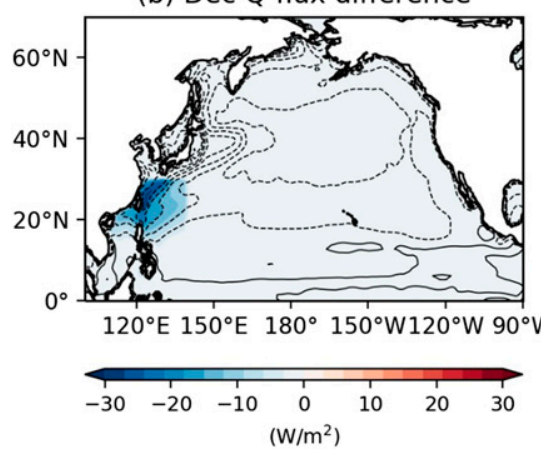

(c) Nov Z200 WAF difference

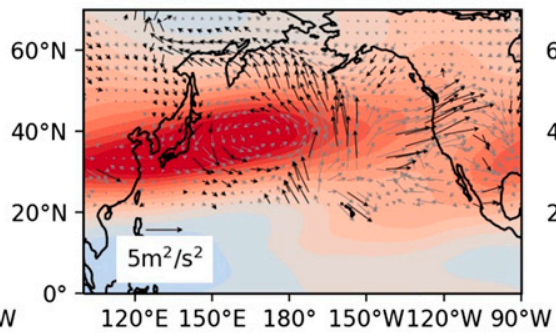

(d) Dec Z200 WAF difference

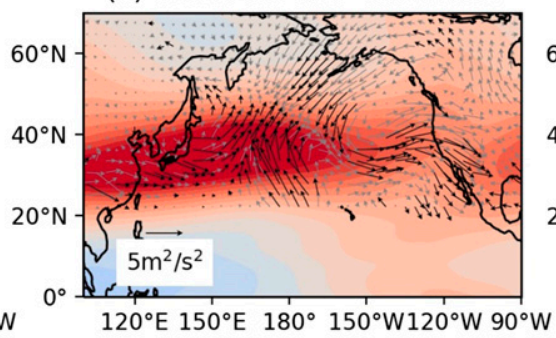

(e) Nov Z500 WAF difference

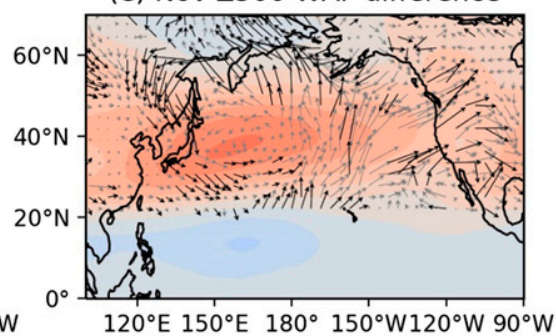

(f) Dec Z500 WAF difference

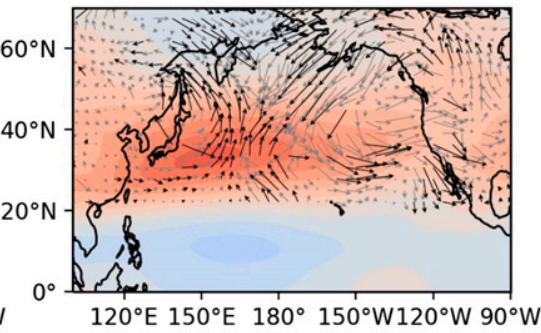

FIG. 11. (a) The $Q$-flux forcing (color shading) added in the experiment run in November. (b) As in (a), but in December. The contour lines denote the $Q$-flux fields in control simulation (ranging from -400 to $100 \mathrm{~W} \mathrm{~m}^{-2}$ with interval $50 \mathrm{~W} \mathrm{~m}^{-2}$ ); the dashed lines indicate negative values and the solid line positive values (positive is downward). (c) The 200-hPa WAF differences (arrows) between the experiment and control runs in November. Background zonal velocity in the control run is superimposed (color shadings). (d) As in (c), but in December. (e),(f) As in (c),(d), but for 500-hPa WAF differences and background zonal velocity. Note that $p<1$ is shown as black arrows.

how the NPO initiates ENSO through the seasonal footprinting mechanism (Chang et al. 2007; Ding et al. 2015a; Ding et al. 2015b). Here, we identified how equatorward cold air associated with the November EAWM initiation can generate diabatic heating anomalies above the
Kuroshio. These anomalies are due to the atmospheric boundary layer response to the ocean front and generate a significant Rossby wave source. The evolution of the Rossby wave train in the middle to upper troposphere then affects the NPO's southern lobe (near Hawaii over (a) Nov Z200 mean difference

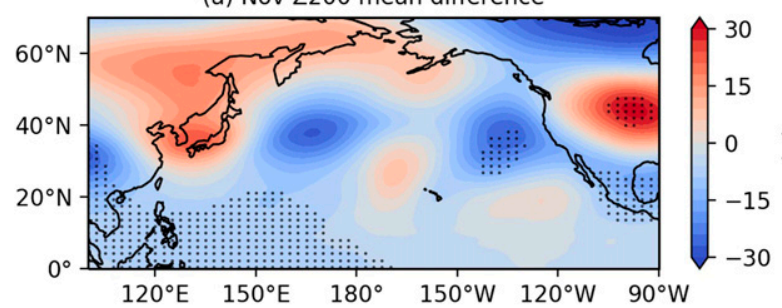

(b) Nov Z500 mean difference

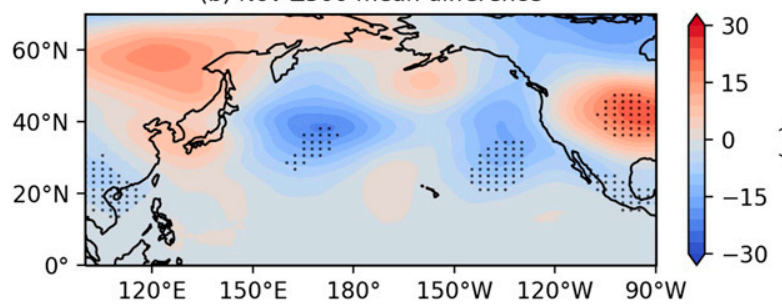

(c) Nov OLR mean difference

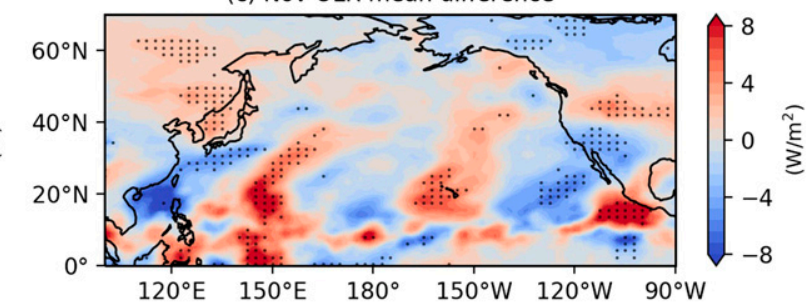

(d) Jan SLP mean difference

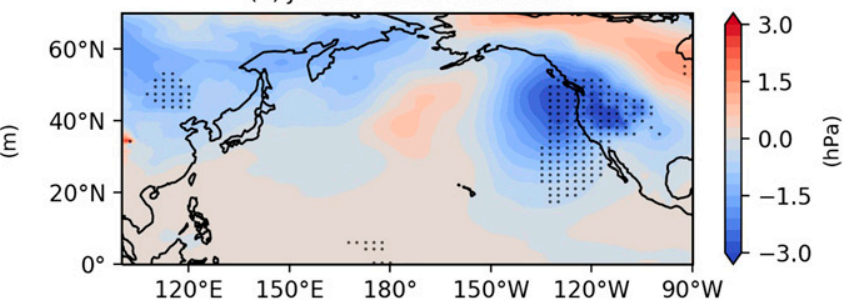

FIG. 12. Simulated differences between the heating experiment and control run. (a) The mean geopotential height differences at $200 \mathrm{hPa}$ in November. (b) As in (a), but for $500 \mathrm{hPa}$. (c) The OLR difference in November. (d) The sea level pressure differences in January. Note that $p<0.1$ is shown as dots. 
the southern branch of the VM). This leads to the growth of a winter NPO southern lobe (maximum in January). Finally, the southern lobe of the NPO forces the surface sea surface temperature footprint of VM in the following spring (Ding et al. 2015a).

The Kuroshio plays a crucial role with regard to the heating source discussed above. The Kuroshio is a strong poleward warm ocean current in the western North Pacific with a large transfer of heat from the ocean to the atmosphere (Tseng et al. 2012; Yang et al. 2015). The large temperature gradient near the edge of the current produces significant atmospheric changes when the EAWM is initiated, and the strong northerly starts to intrude into the Philippine Sea from cold to warm air. The air-sea interface changes from stable to unstable across the Kuroshio front, producing a significant heating source just downstream of the Kuroshio front (divergence/convergence at lower/ upper-level atmosphere with strong negative OLR anomalies in Fig. 8). The negative OLR anomalies indicate a strong and deep convection. The other strong convergence can also be found further downstream of the Kuroshio front at the lower troposphere. This confirms the typical frontal air-sea interaction of the ocean front interacting with the atmosphere (Chelton et al. 2004; Small et al. 2008).

Our results provide additional evidence that the marine boundary layer structure can be systematically modified across the Kuroshio due to changes in surface stability as the cold air flows across the SST gradient. Instability over the warm water leads to an increased vertical exchange of momentum as well as to the establishment of winds and the sea level pressure dipole (Fig. 5a). The stronger northeasterly winds and larger heat fluxes from the ocean to the atmosphere over the warm Kuroshio can generate heating sources in the Philippine Sea leading to further atmospheric changes in the eastern North Pacific. This pathway is further evaluated by the observations and the theoretical wave ray tracing analyses.

The modeling experiments also confirm the underlying Rossby wave propagation and show the direct impact of the additional heating in modulating the southern lobe of the NPO through the Rossby wave train development on the time scale of one month or less (time scale within 20 days). However, we note that the maximum correlation is seen in January due to the continuous evolving. Indeed, the triggering of the EAWM initiation already starts in December. A significant correlation in the central Pacific can be found at 500 and 1000 hPa (Fig. 7), but the correlation continuously increases and reaches its maximum in January when the NPO is mature or even later (Fig. 4). This suggests that the wave propagation occurs in the mid- to the upper troposphere.

Other local processes (e.g., Fig. 8) are continuous and can enhance the local convergence/divergence including the continuously generated Rossby wave sources triggered by the EAWM initiation's sudden change in the Philippine Sea and potential development of barotropic structure in the southern lobe of the NPO. These processes also require time to evolve-specifically the interaction with the sea surface temperature leading to the spring VM [see Ding et al. (2015a) for more discussion] or the heating source in the Philippine Sea.

We found that significant Rossby wave sources are generated and associated with the EAWM initiation in the Philippine Sea. The heating source in the atmosphere results from the ocean front-atmosphere interaction, and we further confirm that the variability of November EAWM is also highly associated with the local sea surface temperature anomalies variability in the Philippine Sea $(R=0.63)$. Similar lag correlation maps are based on the November sea surface temperature index defined in Wang et al. (2012) and superimposed in Fig. 5 as thick dashed contours (blue and red dashes represent $R=0.5$ and 0.4 , respectively). The spatial patterns are quite similar to the maps based on the November EAWMI with very high correlations. The consistent relationship with local sea surface temperature anomalies is not surprising and results mainly from the atmospheric heating changes due to the typical interactions of the ocean front and atmosphere described above.

Wang et al. (2012) suggested that the surface winds in the Philippine Sea occur almost at the same time as the NPO from December to February (Fig. 4 in Wang et al. 2012). Based on our monthly observational data that used wave ray tracking analyses and model sensitivity experiments instead of a 3-month mean, we further clarify that the southern lobe of winter NPO can be intensified through the middle to upper tropospheric Rossby wave propagation from the Philippine Sea. This forces the following spring basin-scale VM in the North Pacific over the southern branch of the VM. This is consistent with the tight connection between the WP and NPO and their vertical structure (Linkin and Nigam 2008). Thus, we conclude that the origin of the NPO and WP variability is directly linked with the atmospheric boundary layer heating changes in the Philippine Sea related to the EAWM.

However, the EAWM may not be the only factor influencing the NPO variability in general. Synoptic eddymean flow interactions or transient eddies may also affect the NPO variability (Linkin and Nigam 2008). Further analysis of the 13-yr running correlation coefficient between the EAWM and $\mathrm{NPO}_{S_{\mathrm{St}}}$ variability confirmed that the two indices were nicely correlated after late 1970s with increasing correlation after the late 1980s (Fig. 6b); these are poorly correlated during the mid-1970s consistent with the nonstationary connection with the EAWM and the 
intensified circumglobal wave train activity after 1975 (Wang et al. 2007; Pak et al. 2014). Other stochastic processes may also exist. Nevertheless, our results are quite robust throughout the entire time period with significant impacts for all time periods with increasing correlation after 1979. The decadal-scale increasing trend is also confirmed using an even lower-frequency running windows (data not shown).

Further analysis suggests that the November EAWMI varies simultaneously with the SCS winds and extends northward to the east edge of the Ryukyu Islands with a correlation larger than 0.85 (Fig. 5a). A one-month lag correlation map of December suggests that the November EAWM intensifies the local cyclonic circulation over the Maritime Continent (Fig. 5b) thus leading to the eastern Pacific teleconnection pattern in January (Fig. 5c). These results show that the strengthening of northeasterly winds associated with the EAWM initiation flowing over the Kuroshio front during the early winter may generate the heating anomalies to modulate the NPO variability. Therefore, the oceanatmosphere interaction due to the Kuroshio front can be identified as a key factor to modify the NPO's south lobe variability regardless of the nonstationary link between the EAWM and NPO.

\section{Conclusions and future work}

We investigate the origin of the NPO variability and its potential pathways linking directly to the initiation of EAWM. This pathway is further confirmed via wave ray tracing analyses and modeling experiments. The schematic in Fig. 13 summarizes the underlying dynamical processes triggered by the initiation of EAWM. The variability of the southern lobe of the NPO can be initiated by the November EAWM associated with the heating anomalies above the Kuroshio front in the Philippine Sea (step 1 in November). This leads to the local deep convection change in the western North Pacific in the following months (step 2 in November and December). Therefore, the NPO is not directly connected with the EAWM; it is only connected through its subtropical initiation interacting with the Kuroshio (i.e., the sea surface temperature gradient across the ocean front). The continuously generated Rossby wave sources propagate northeastward in winter to enhance the subsidence near the southern branch of the VM until the matured NPO (step 3 in DecemberJanuary). This is followed by a typical negative phase of NPO forced VM in the Northern Hemisphere forming the combined sea surface pattern of CEOF2 (step 4 in late winter to spring; details are already given in prior works). Our results nicely explain the previous precursor linkage of the western North Pacific sea surface temperatures to

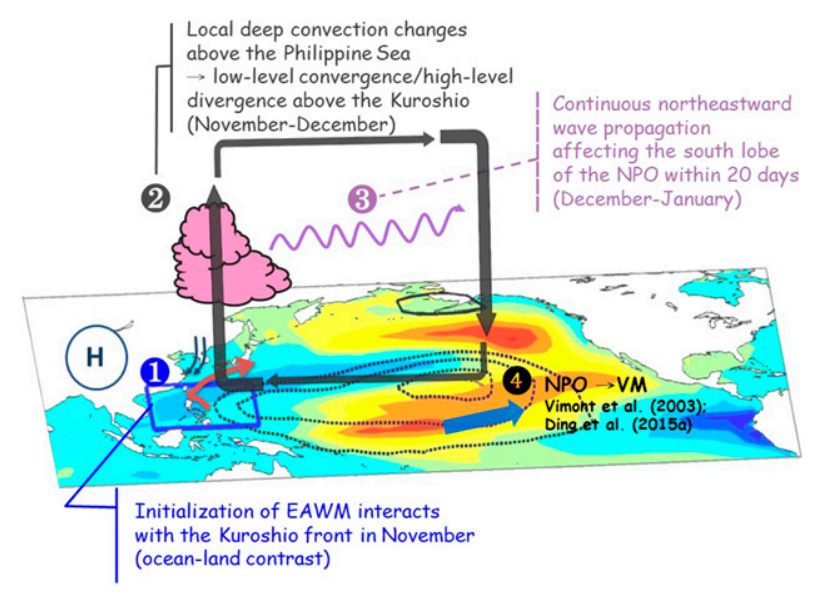

FIG. 13. Schematic diagram of the dynamical processes linking the initiation of EAWM and the southern lobe of NPO. The sea level pressure (contours) and sea surface temperature anomalies associated with the CEOF2 patterns are overlaid.

ENSO variability (Wang et al. 2012; Tseng et al. 2017) due to the NPO-like teleconnection (specifically the southern lobe of the NPO). These processes are robust regardless of the length of the analysis years and the datasets. The wave propagation is on a one-month time scale or less.

Our results identify the initiation of EAWM connected directly to the local air-sea interaction between the Kuroshio front and the atmosphere. This enhances the deep convection. Both the wave ray tracing analyses and CGCM experiments confirm the proposed pathway influencing the southern lobe of the NPO. The origin of the wave rays is the western North Pacific with a clear eastward propagating trajectories reaching the centraleastern subtropical Pacific over the southern branch of the VM (near the southern lobe of the NPO) in the midto upper troposphere. This is consistent with the WAF differences in the modeling experiments and is different from the wave ray trajectories in the lower troposphere (flows are mostly westward and never reach the eastern Pacific).

The observations, wave raying tracing analyses, and coupled modeling experiments show no obvious link with the northern lobe of the NPO in the dynamical processes: the atmospheric teleconnection primarily affects the southern lobe of the NPO. Although the described pathway due to the Rossby wave propagation is within a month, the local processes require time to develop the barotropic structure of the WP and NPO patterns. The deep convection resulting from the initiation of EAWM is continuously generated in winter from the continuous ocean-atmosphere interactions; therefore, the observation shows a maximum January correlation in the central-eastern Pacific that relates to the development of the southern lobe of the NPO rather 
than the NPO dipole. Further studies are needed to identify the variability of the northern lobe of the NPO in a follow-up study. Such a study will be directly related to the Siberian high and Arctic variability.

Acknowledgments. We thank three anonymous reviewers for their constructive comments that have helped to improve the clarity of the presentation. This study was supported by the MOST Grants 107-2611-M-002013-MY4 and 108-2111-M-002-006 -MY3, Taiwan.

\section{REFERENCES}

Bond, N. A., J. E. Overland, M. Spillane, and P. Stabeno, 2003: Recent shifts in the state of the North Pacific. Geophys. Res. Lett., 30, 2183, https://doi.org/10.1029/2003GL018597.

Bretherton, C. S., M. Widmann, V. P. Dymnikov, J. M. Wallace, and I. Bladé, 1999: The effective number of spatial degrees of freedom of a time-varying field. J. Climate, 12, 1990-2009, https:// doi.org/10.1175/1520-0442(1999)012<1990:TENOSD>2.0.CO;2.

Chang, P., L. Zhang, R. Saravanan, D. J. Vimont, J. C. H. Chiang, L. Ji, H. Seidel, and M. K. Tippett, 2007: Pacific meridional mode and El Niño-Southern Oscillation. Geophys. Res. Lett., 34, L16608, https://doi.org/10.1029/2007GL030302.

Chelton, D. B., M. Schlax, M. Freilich, and R. Milliff, 2004: Satellite measurements reveal persistent small-scale features in ocean winds. Science, 303, 978-983, https://doi.org/10.1126/science.1091901.

Chen, W., H. Graf, and R. Huang, 2000: The interannual variability of East Asian winter monsoon and its relation to the summer monsoon. Adv. Atmos. Sci., 17, 48-60, https://doi.org/10.1007/ s00376-000-0042-5.

Chow, C. H., Y.-H. Tseng, H.-H. Hsu, and C.-C. Young, 2017: The interannual variability of the subtropical countercurrent's eddies in the North Pacific associated with the Western-Pacific teleconnection pattern. Cont. Shelf Res., 143, 175-184, https:// doi.org/10.1016/j.csr.2016.08.006.

Compo, G. P., G. Kiladis, and P. Webster, 1999: The horizontal and vertical structure of East Asian winter monsoon pressure surges. Quart. J. Roy. Meteor. Soc., 125, 29-54, https://doi.org/10.1002/ qj.49712555304.

_ J. S. Whitaker, P. D. Sardeshmukh, N. Matsui, R. J. Allan, and X. Yin, 2011: The Twentieth Century Reanalysis Project. Quart. J. Roy. Meteor. Soc., 137, 1-28, https://doi.org/10.1002/ qj.776.

Danabasoglu, G., and P. R. Gent, 2009: Equilibrium climate sensitivity: Is it accurate to use a slab ocean model? J. Climate, 22, 2494-2499, https://doi.org/10.1175/2008JCLI2596.1.

Di Lorenzo, E., and N. J. Mantua, 2016: Multi-year persistence of 2014/15 North Pacific marine heatwave. Nat. Climate Change, 6, 1042-1047, https://doi.org/10.1038/nclimate3082.

—_, and Coauthors, 2008: North Pacific Gyre Oscillation links ocean climate and ecosystem change. Geophys. Res. Lett., $\mathbf{3 5}$, L08607, https://doi.org/10.1029/2007GL032838.

— , K. M. Cobb, J. C. Furtado, N. Schneider, B. T. Anderson, A. Bracco, M. A. Alexander, and D. J. Vimont, 2010: Central Pacific El Niño and decadal climate change in the North Pacific. Nat. Geosci., 3, 762-765, https://doi.org/10.1038/ngeo984.

Ding, R., J. Li, Y. H. Tseng, C. Sun, and Y. Guo, 2015a: The Victoria mode in the North Pacific linking extratropical sea level pressure variations to ENSO. J. Geophys. Res. Atmos., 120, 27-45, https://doi.org/10.1002/2014JD022221.
,,--- , and C. Ruan, 2015b: Influence of the North Pacific Victoria mode on the Pacific ITCZ summer precipitation. J. Geophys. Res. Atmos., 120, 964-979, https://doi.org/10.1002/ 2014JD022364.

,,,--- C. Sun, and F. Zheng, 2017: Linking a sea level pressure anomaly dipole over the North America to the central Pacific El Niño. Climate Dyn., 49, 1321-1339, https:// doi.org/10.1007/s00382-016-3389-8.

,,,,---- Y Y. Li, N. Xing, and X. Li, 2019: Linking the North American dipole to the Pacific meridional mode. J. Geophys. Res. Atmos., 124, 3020-3034, https://doi.org/ 10.1029/2018JD029692.

Furtado, J. C., E. Di Lorenzo, B. T. Anderson, and N. Schneider, 2012: Linkages between the North Pacific Oscillation and central tropical Pacific SSTs at low frequencies. Climate Dyn., 39, 2833-2846, https://doi.org/10.1007/s00382-011-1245-4.

Hoskins, B. J., and D. J. Karoly, 1981: The steady linear response of a spherical atmosphere to thermal and orographic forcing. J. Atmos. Sci., 38, 1179-1196, https://doi.org/10.1175/15200469(1981)038<1179:TSLROA > 2.0.CO;2.

_ , and T. Ambrizzi, 1993: Rossby wave propagation on a realistic longitudinally varying flow. J. Atmos. Sci., 50, 1661-1671, https:// doi.org/10.1175/1520-0469(1993)050<1661:RWPOAR > 2.0.CO;2.

Hurrell, J. W., and Coauthors, 2013: The Community Earth System Model: A framework for collaborative research. Bull. Amer. Meteor. Soc., 94, 1339-1360, https://doi.org/10.1175/BAMS-D12-00121.1.

Kalnay, E., and Coauthors, 1996: The NCEP/NCAR 40-Year Reanalysis Project. Bull. Amer. Meteor. Soc., 77, 437-471, https:// doi.org/10.1175/1520-0477(1996)077<0437:TNYRP>2.0.CO;2.

Kistler, R., and Coauthors, 2001: The NCEP-NCAR 50-Year Reanalysis: Monthly means CD-ROM and documentation. Bull. Amer. Meteor. Soc., 82, 247-267, https://doi.org/10.1175/ 1520-0477(2001)082<0247:TNNYRM > 2.3.CO;2.

Leung, M. Y. T., and W. Zhou, 2015: Vertical structure, physical properties, and energy exchange of the East Asian trough in boreal winter. Climate Dyn., 45, 1635-1656, https://doi.org/ 10.1007/s00382-014-2419-7.

Li, Y., J. Li, F.-F. Jin, and S. Zhao, 2015: Interhemispheric propagation of stationary Rossby waves in the horizontally nonuniform background flow. J. Atmos. Sci., 72, 3233-3256, https:// doi.org/10.1175/JAS-D-14-0239.1.

Linkin, M. E., and S. Nigam, 2008: The North Pacific Oscillationwest Pacific teleconnection pattern: Mature-phase structure and winter impacts. J. Climate, 21, 1979-1997, https://doi.org/ 10.1175/2007JCLI2048.1.

Neale, R. B., and Coauthors, 2012: Description of the NCAR Community 10 Atmosphere Model (CAM 5.0). NCAR Tech. Note NCAR-TN-486+STR, 274 pp., www.cesm.ucar.edu/ models/cesm1.0/cam/docs/description/cam5_desc.pdf.

Pak, G., Y.-H. Park, F. Vivier, Y.-O. Kwon, and K.-I. Chang, 2014: Regime-dependent nonstationary relationship between the East Asian winter monsoon and North Pacific Oscillation. J. Climate, 27, 8185-8204, https://doi.org/10.1175/JCLI-D-13-00500.1.

Plumb, R. A., 1985: On the three-dimensional propagation of stationary waves. J. Atmos. Sci., 42, 217-229, https://doi.org/10.1175/ 1520-0469(1985)042<0217:OTTDPO > 2.0.CO;2.

Rogers, J. C., 1981: The North Pacific Oscillation. Int. J. Climatol., 1, 39-57, https://doi.org/10.1002/joc.3370010106.

Sardeshmukh, P. D., and B. J. Hoskins, 1988: The generation of global rotation flow by steady idealized tropical divergence. J. Atmos. Sci., 45, 1228-1251, https://doi.org/10.1175/15200469(1988)045<1228:TGOGRF>2.0.CO;2. 
Shaman, J., and E. Tziperman, 2005: The effect of ENSO on Tibetan Plateau snow depth: A stationary wave teleconnection mechanism and implications for the South Asian monsoons. J. Climate, 18, 2067-2079, https://doi.org/10.1175/JCLI3391.1.

Small, R. J., and Coauthors, 2008: Air-sea interaction over ocean fronts and eddies. Dyn. Atmos. Oceans, 45, 274-319, https:// doi.org/10.1016/j.dynatmoce.2008.01.001.

Smith, T. M., R. W. Reynolds, T. C. Peterson, and J. Lawrimore, 2008: Improvements to NOAA's historical merged land-ocean surface temperature analysis (1880-2006). J. Climate, 21, 22832296, https://doi.org/10.1175/2007JCLI2100.1.

Takaya, K., and H. Nakamura, 2001: A formulation of a phaseindependent wave-activity flux for stationary and migratory quasigeostrophic eddies on a zonally varying basic flow. J. Atmos. Sci., 58, 608-627, https://doi.org/10.1175/15200469(2001)058<0608:AFOAPI >2.0.CO;2.

Tseng, Y.-H., M.-L. Shen, S. Jan, D. E. Dietrich, and C.-P. Chiang, 2012: Validation of the Kuroshio current system in the dualdomain Pacific Ocean model framework. Prog. Oceanogr., 105, 102-124, https://doi.org/10.1016/j.pocean.2012.04.003.

— , R. Ding, and X.-M. Huang, 2017: The warm blob in the northeast Pacific-The bridge leading to the 2015/16 El Niño. Environ. Res. Lett., 12, 054019, https://doi.org/10.1088/17489326/aa67c3.

Vimont, D. J., J. M. Wallace, and D. S. Battisti, 2003: The seasonal footprinting mechanism in the Pacific: Implications for ENSO. J. Climate, 16, 2668-2675, https://doi.org/10.1175/1520-0442(2003) 016<2668:TSFMIT >2.0.CO;2.

Walker, G. T., and E. W. Bliss, 1932: World weather V. Mem. Roy. Meteor. Soc., 4, 53-84.

Wallace, J. M., and D. S. Gutzler, 1981: Teleconnections in the geopotential height field during the Northern Hemisphere winter. Mon. Wea. Rev., 109, 784-812, https://doi.org/10.1175/ 1520-0493(1981)109<0784:TITGHF $>2.0$. CO;2.

Wang, B., 2006: The Asian Monsoon. Springer, 787 pp.

- R. Wu, and X. Fu, 2000: Pacific-East Asian teleconnection: How does ENSO affect East Asian climate? J. Climate, 13, 1517-1536, https://doi.org/10.1175/1520-0442(2000)013<1517: PEATHD $>2.0 . \mathrm{CO} ; 2$.
_ Z Z. Wu, C.-P. Chang, J. Liu, J. Li, and T. Zhou, 2010: Another look at interannual-to-interdecadal variations of the East Asian winter monsoon: The northern and southern temperature modes. J. Climate, 23, 1495-1512, https://doi.org/10.1175/ 2009JCLI3243.1.

Wang, L., and W. Chen, 2010: How well do existing indices measure the strength of the East Asian winter monsoon? Adv. Atmos. Sci., 27, 855-870, https://doi.org/10.1007/s00376-009-9094-3.

,-- , and R. Huang, 2007: Changes in the variability of North Pacific Oscillation around 1975/1976 and its relationship with East Asian winter climate. J. Geophys. Res., 112, D11110, https://doi.org/10.1029/2006JD008054.

Wang, S. Y., M. L'Heureux, and H. H. Chia, 2012: ENSO prediction one year in advance using western North Pacific sea surface temperatures. Geophys. Res. Lett., 39, L05702, https:// doi.org/10.1029/2012GL050909.

_- W. Huang, and H. J. Yoon, 2015: The North American winter 'dipole' and extremes activity: A CMIP5 assessment. Atmos. Sci. Lett., 16, 338-345, https://doi.org/10.1002/ as12.565.

Whitham, G., 1960: A note on group velocity. J. Fluid Mech., 9, 347-352, https://doi.org/10.1017/S0022112060001158.

Yang, S., K.-M. Lau, and K.-M. Kim, 2002: Variations of the East Asian jet stream and Asian-Pacific-American winter climate anomalies. J. Climate, 15, 306-325, https://doi.org/10.1175/ 1520-0442(2002)015<0306:VOTEAJ > 2.0.CO;2.

Yang, Y. J., and Coauthors, 2015: Mean structure and fluctuations of the Kuroshio east of Taiwan from in situ and remote observations. Oceanography, 28, 74-83, https://doi.org/10.5670/ oceanog.2015.83.

Zhao, S., J. Li, and Y. Li, 2015: Dynamics of an interhemispheric teleconnection across the critical latitude through a southerly duct during boreal winter. J. Climate, 28, 7437-7456, https:// doi.org/10.1175/JCLI-D-14-00425.1.

,,,--- F.-F. Jin, and J. Zheng, 2019: Interhemispheric influence of Indo-Pacific convection oscillation on Southern Hemisphere rainfall through southward propagation of Rossby waves. Climate Dyn., 52, 3203-3221, https://doi.org/10.1007/ s00382-018-4324-y. 